\title{
Interneurons Differentially Contribute to Spontaneous Network Activity in the Developing Hippocampus Dependent on Their Embryonic Lineage
}

\author{
ㄱoson C. Wester and $\mathbb{C}^{C}$ Chris J. McBain \\ Program in Developmental Neurobiology, Eunice Kennedy Shriver National Institute of Child Health and Human Development (NICHD), National \\ Institutes of Health, Bethesda, Maryland 20892
}

\begin{abstract}
Spontaneously generated network activity is a hallmark of developing neural circuits, and plays an important role in the formation of synaptic connections. In the rodent hippocampus, this activity is observed in vitro as giant depolarizing potentials (GDPs) during the first postnatal week. Interneurons importantly contribute to GDPs, due to the depolarizing actions of GABA early in development. While they are highly diverse, cortical interneurons can be segregated into two distinct groups based on their embryonic lineage from either the medial or caudal ganglionic eminences (MGE and CGE). There is evidence suggesting CGE-derived interneurons are important for GDP generation; however, their contribution relative to those from the MGE has never been directly tested. Here, we optogenetically inhibited either MGE- or CGE-derived interneurons in a region-specific manner in mouse neonatal hippocampus in vitro. In CA1, where interneurons are the primary source of recurrent excitation, we found that those from the MGE strongly and preferentially contributed to GDP generation. Furthermore, in dual whole-cell patch recordings in neonatal CA1, MGE interneurons formed synaptic connections to and from neighboring pyramidal cells at a much higher rate than those from the CGE. These MGE interneurons were commonly perisomatic targeting, in contrast to those from the CGE, which were dendrite targeting. Finally, inhibiting MGE interneurons in CA1 suppressed GDPs in CA3 and vice versa; conversely, they could also trigger GDPs in CA1 that propagated to CA3 and vice versa. Our data demonstrate a key role for MGE-derived interneurons in both generating and coordinating GDPs across the hippocampus.
\end{abstract}

Key words: giant depolarizing potential; hippocampus; interneurons

Significance Statement

During nervous system development, immature circuits internally generate rhythmic patterns of electrical activity that promote the establishment of synaptic connections. Immature interneurons are excitatory rather than inhibitory and actively contribute to the generation of these spontaneous network events, referred to as giant depolarizing potentials (GDPs) in the hippocampus. Interneurons can be generally separated into two distinct groups based on their origin in the embryo from the medial or caudal ganglionic eminences (MGE and CGE). Here we show that MGE interneurons play a dominant role in generating GDPs compared with their CGE counterparts. They accomplish this due to their high synaptic connectivity within the local circuitry. Finally, they can control network activity across large regions of the developing hippocampus.

\section{Introduction}

The developing nervous system intrinsically generates stereotyped patterns of electrical activity thought to be important for establishing mature circuitry. This activity varies at different developmental stages, culminating in giant depolarizing potentials (GDPs), which coincide with synaptogenesis (Ben-Ari, 2001).

\footnotetext{
Received Nov. 5, 2015; revised Jan. 19, 2016; accepted Jan. $27,2016$.

Author contributions: J.C.W. and C.J.M. designed research; J.C.W. performed research; J.C.W. analyzed data; J.C.W. and C.J.M. wrote the paper.

This work was supported by a NICHD Intramural Award to C.J.M. and a National Institute of Neurological Disorders and Stroke Competitive Fellowship Award to J.C.W.

The authors declare no competing financial interests.
}

GDPs consist of rhythmic bouts of sustained polysynaptic activity lasting several hundred milliseconds and traveling as a wave. Variants of this activity have been observed throughout the nervous system in vitro, including the spinal cord (Gonzalez-Islas and Wenner, 2006), cochlea (Tritsch et al., 2007), retina (Meister et al., 1991), hippocampus (Ben-Ari et al., 1989), and neocortex (Garaschuk et al., 2000). In rodent hippocampus, GDPs are observed shortly after birth, peak near the end of the first postnatal

Correspondence should be addressed to Dr. Chris J. McBain, Program in Developmental Neurobiology, NICHD, National Institutes of Health, Bethesda, MD 20892. E-mail: mcbainc@mail.nih.gov.

DOI:10.1523/JNEUROSCI.4000-15.2016

Copyright $\odot 2016$ the authors $\quad 0270-6474 / 16 / 362646-17 \$ 15.00 / 0$ 
week, and are subsequently replaced by mature network rhythms (Ben-Ari, 2001).

The circuit mechanisms responsible for generating GDPs vary by structure; however, depolarizing GABA from local interneurons, mediated by an immature chloride gradient, is a common component (Ben-Ari et al., 2007; Blankenship and Feller, 2010). Recurrent excitation among interneurons and principal cells has been best studied in the hippocampus, as GDPs were originally described in area CA3 (Ben-Ari et al., 1989). In this region, pyramidal cells (PCs) are highly interconnected, even early in development (Li et al., 1994; Bolea et al., 1999). Depolarization from local interneurons can cause PCs to generate intrinsic bursts of action potentials, which leads to GDP initiation and propagation throughout the hippocampus (Sipilä et al., 2005; Bolea et al., 2006; Sipilä et al., 2006). Importantly, connections among CA1 PCs are sparse (Knowles and Schwartzkroin, 1981; Deuchars and Thomson, 1996), yet this region is also capable of generating GDPs, even when disconnected from CA3 (Garaschuk et al., 1998; Menendez de la Prida et al., 1998). Thus, CA1 is an interesting model system for studying interneurons as a primary source of immature recurrent excitation.

In mature circuits, interneurons are incredibly diverse in terms of electrophysiology and morphology, and play distinct roles in regulating neural activity (Klausberger and Somogyi, 2008; DeFelipe et al., 2013; Wester and McBain, 2014). Recently, it was discovered that distinct subsets of cortical interneurons are generated during embryonic development from the medial ganglionic eminences (MGEs) and caudal ganglionic eminences (CGEs) (Butt et al., 2005; Miyoshi et al., 2010; Tricoire et al., 2011). Hippocampal MGE-derived interneurons include fastspiking, parvalbumin (PV)-expressing basket and axo-axonic cells, somatostatin (SOM)-expressing cells that target the apical dendritic tree, ivy cells, and a subset of neurogliaform cells. CGEderived interneurons are equally diverse and include those that express cholecystokinin (CCK), reelin, calretinin, and vasointestinal peptide (VIP). Many are dendrite targeting; however, a subset of CCK-expressing interneurons includes non-fast-spiking basket cells. It is possible that, during early postnatal development, specific interneuron subtypes differentially contribute to generating GDPs. Indeed, a prevailing model is that calretininand CCK-expressing interneurons targeting the dendrites of PCs are the primary drivers of GDPs, whereas perisomatic targeting cells, including PV-expressing baskets, act to suppress GDPs at later time points when the circuitry matures and GABA becomes shunting (Ben-Ari et al., 2007). Thus, one hypothesis is that CGEderived interneurons play a privileged role in producing early spontaneous network activity.

Here, we directly test the relative contributions of MGE- versus CGE-derived interneurons in CA1 by selectively inhibiting them using optogenetics. We find that, contrary to expectations, inhibition of MGE-derived interneurons strongly suppresses ongoing spontaneous GDPs, whereas those derived from the CGE have a smaller impact. Supporting this finding, MGE-derived interneurons have a higher rate of synaptic connectivity with neighboring PCs in CA1 than those from the CGE. Finally, modulation of MGE-derived interneuron activity in CA1 affects GDPs in CA3 and vice versa. Our data suggest that GDPs are coordinated across hippocampal subfields and that MGEderived interneurons play a prominent role in regulating this activity.

\section{Materials and Methods}

Animals. All experiments were conducted in accordance with animal protocols approved by the National Institutes of Health. We used male and female Nkx2-1-cre:RCE or Nkx2-1-cre:Ai14 mice to target MGEderived interneurons and Htr3a-GFP or GAD65-GFP mice to target CGE-derived interneurons. Ail4 mice express a cre-dependent tdTomato reporter (The Jackson Laboratory, stock \#007908). For optogenetic experiments, Nkx2-1-cre:Ail4 and Htr3a-cre:Ai14 mice were crossed with Ai35D mice, which express cre-dependent archearhodopsin (Arch)-GFP (The Jackson Laboratory, stock \#012735), to inhibit MGEand CGE-derived interneurons, respectively.

Slice preparation. Neonatal ( $\mathrm{p} 5-\mathrm{p} 8)$ or juvenile (p11-p21) mice were anesthetized with isoflurane and then decapitated. The brain was dissected out in ice-cold ACSF containing the following (in mM): 100 sucrose, $80 \mathrm{NaCl}, 3.5 \mathrm{KCl}, 24 \mathrm{NaHCO}_{3}, 1.25 \mathrm{NaH}_{2} \mathrm{PO}_{4}, 4.5 \mathrm{MgCl}, 0.5$ $\mathrm{CaCl}_{2}$, and 10 glucose, saturated with $95 \% \mathrm{O}_{2}$ and $5 \% \mathrm{CO}_{2}$. Horizontal hippocampal slices $(300 \mu \mathrm{m})$ were cut using a VT-1000S vibratome (Leica Microsystems) and incubated in the above solution at $35^{\circ} \mathrm{C}$ for $30-60 \mathrm{~min}$. Slices were maintained at room temperature until use, either in the above solution or in recording ACSF consisting of the following (in $\mathrm{mm}$ ): $130 \mathrm{NaCl}, 3.5 \mathrm{KCl}, 24 \mathrm{NaHCO}_{3}, 1.25 \mathrm{NaH}_{2} \mathrm{PO}_{4}, 1.5 \mathrm{MgCl}, 2.5$ $\mathrm{CaCl}_{2}$, and 10 glucose, saturated with $95 \% \mathrm{O}_{2}$ and $5 \% \mathrm{CO}_{2}$.

Electrophysiology. For recording, slices were transferred to an upright microscope (Zeiss Axioskop 2), perfused at $2 \mathrm{ml} / \mathrm{min}$, and maintained at a temperature of $32^{\circ} \mathrm{C}-34^{\circ} \mathrm{C}$. Electrodes were pulled from borosilicate glass (World Precision Instruments) to a resistance of 3-5 $\mathrm{m} \Omega$ using a vertical pipette puller (Narishige, PP-830). Whole-cell patch-clamp recordings were made using a Multiclamp 700A amplifier (Molecular Devices), filtered at $3 \mathrm{kHz}$ (Bessel filter), and digitized at $20 \mathrm{kHz}$ (Digidata 1322A or 1550 and pClamp 9.2 or 10.4 software; Molecular Devices). Recordings were not corrected for a liquid junction potential. Uncompensated series resistance during recordings ranged from 10 to $25 \mathrm{M} \Omega$ and was monitored continuously throughout with $-5 \mathrm{mV}$ voltage steps. In current-clamp mode, cells were biased to $-70 \mathrm{mV}$; in voltage-clamp mode, a holding potential of $-70 \mathrm{mV}$ was applied. For whole-cell recordings, internal solutions used were as follows. Glutamatergic currents and potentials were recorded with electrodes containing the following (in mM): $130 \mathrm{~K}$-gluconate, $5 \mathrm{KCl}, 3 \mathrm{MgCl}, 2 \mathrm{Na}_{2} \mathrm{ATP}, 0.3 \mathrm{NaGTP}, 10 \mathrm{HEPES}$, 0.6 EGTA, and $0.2 \%$ biocytin. The calculated $E_{\mathrm{Cl}-}$ (chloride reversal potential) for this solution was $-67 \mathrm{mV}$. To record GABA(A)-mediated currents in voltage-clamp at a holding potential of $-70 \mathrm{mV}$, we used one of two different internal solutions. For some experiments, electrodes contained the following (in $\mathrm{mm}$ ): $130 \mathrm{KCl}, 8.5 \mathrm{NaCl}, 4 \mathrm{MgATP}, 0.3$ NaGTP, 5 HEPES, 0.5 EGTA, and $0.2 \%$ biocytin, for a calculated $E_{\mathrm{Cl}-}$ of $0 \mathrm{mV}$. Alternatively, electrodes contained the following (in $\mathrm{mM}$ ): 100 K-gluconate, $45 \mathrm{KCl}, 3 \mathrm{MgCl}, 2 \mathrm{Na}_{2} \mathrm{ATP}, 0.3 \mathrm{NaGTP}, 10$ HEPES, 0.6 EGTA, and $0.2 \%$ biocytin, for a calculated $E_{\mathrm{Cl}-}$ of $-27 \mathrm{mV}$. In some experiments, biocytin was left out of the internal solution when recording pyramidal cells. Osmolarity of internal solutions was adjusted to $\sim 290$ mOsm with sucrose; the $\mathrm{pH}$ was adjusted to 7.4 with $\mathrm{KOH}$.

For tests of synaptic connectivity using paired recordings, presynaptic cells in current-clamp were made to fire trains of action potentials ( 25 at $50 \mathrm{~Hz}$ ) using 1-2 nA current steps of 1-2 ms duration, every $10 \mathrm{~s}$ for at least 10 trials. Postsynaptic cells were recorded in voltage-clamp at -70 $\mathrm{mV}$. For optogenetic experiments, we focused yellow-green light (545 \pm $15 \mathrm{~nm}$ ) on the region of interest through a $40 \times$ water-immersion objective. Each trial consisted of $10 \mathrm{~s}$ with the light off, followed by $10 \mathrm{~s}$ of the light on, followed by $20 \mathrm{~s}$ of the light off. We waited $30 \mathrm{~s}$ between trials. Input resistance (Rin) was measured using a linear regression of voltage deflections ( $\pm 15 \mathrm{mV}$ from $-70 \mathrm{mV}$ resting potential) in response to $1 \mathrm{~s}$ current steps and was not corrected for seal resistance.

Cuts between CA1 and CA 3 were made under a dissection microscope using a scalpel (\#11 blade) and extended from the alveus through the stratum lacunosum moleculare. Slices were allowed to recover for at least $20 \mathrm{~min}$ after the cut at $32^{\circ} \mathrm{C}-34^{\circ} \mathrm{C}$ before recordings of GDPs were made.

Data analysis. All data were imported into Igor Pro (WaveMetrics) using NeuroMatic (ThinkRandom) and analyzed using custom routines. 
To analyze postsynaptic currents in paired recordings, we first "zeroed" the data by subtracting the baseline and then performed 10 repetitions of binomial (Gaussian) smoothing. All postsynaptic currents (PSCs) were then analyzed relative to the timing of the peak of each presynaptic spike during the train. PSCs were detected by threshold crossing $(-7$ to $-10 \mathrm{pA})$; if this threshold was already crossed at the instant of spike peak, the PSC data associated with that spike of that trial were discarded as being contaminated by spontaneous events. The proportion of failures was calculated as the ratio of evoked PSCs to the total number of noncontaminated trials for each presynaptic spike. The PSC potency was calculated as the average peak amplitude of all successfully evoked PSCs for each presynaptic spike (i.e., failures were not included in the average). To measure the PSC decay time constant, we used an averaged PSC and fit an exponential curve from the peak to return to baseline. We defined PSC latency as the time from the peak of the presynaptic action potential to the inflection point at the onset of the PSC (maximum of the second derivative of the current). We defined PSC jitter as the coefficient of variation of the latency.

To quantify asynchronous GABA release, we used the methods described by Daw et al. (2009). First, we reduced high frequency noise in the postsynaptic response by applying 50 repetitions of binomial (Gaussian) smoothing. We then created an artificial miniature PSC (mPSC) by selecting a recorded mPSC and replacing the decay from peak back to baseline with a fit single exponential curve (this was necessary to remove all noise during the decay). We then calculated a Fourier transform of the artificial mPSC and divided this into the Fourier transform of the full postsynaptic response. Finally, we calculated the inverse Fourier transform of the quotient to return the data to the time domain. The result of these operations was a release rate histogram (originally described by Diamond and Jahr (1995), which represents the probability of vesicle release as a function of time. From an averaged release rate histogram $(\sim 10$ trials), we calculated the ratio of asynchronous to synchronous release for each spike during the train: we considered the area under the curve during the $5 \mathrm{~ms}$ after the onset of the presynaptic current step to include synchronous vesicle release, and the area under the curve for the $15 \mathrm{~ms}$ following this to include asynchronous release (see Fig. $6 B-D$ ).

GDPs were detected by threshold crossing $(-100 \mathrm{pA})$. The beginning and ending of detected events were defined relative to the baseline, and only events representing polysynaptic activity lasting at least $200 \mathrm{~ms}$ were classified as GDPs. For optogenetics experiments, we defined four $10 \mathrm{~s}$ time bins during the each trial: (1) immediately preceding the light stimulus (PreOn), (2) during the light stimulus (On), (3) immediately following the light stimulus (PostOn), and (4) $3 \mathrm{~s}$ after the end of the light stimulus to exclude triggered rebound GDPs (PostOn, PostRebound GDP). If the GDP detection threshold was crossed during the On bin, but the onset of the GDP preceded the light, this event was counted during the PreOn bin. Similarly, if the detection threshold was crossed during the PostOn bin, but the onset of the GDP occurred during the light stimulus, this event was counted during the On time bin. GDPs were considered triggered rebound events if they occurred within $500 \mathrm{~ms}$ of the end of the light stimulus. The charge transfer was calculated by integrating the measured current from GDP onset to return to baseline.

To compare the timing and occurrence of spontaneous GDPs recoded in CA1 and CA3, we used data collected from the PreOn bin during optogenetics experiments.

Anatomic reconstruction. After biocytin filling during whole-cell recordings, slices were fixed with $4 \%$ PFA and stored at $4^{\circ} \mathrm{C}$. After at least $24 \mathrm{~h}$, slices were transferred to PBS. To recover the cells, slices were permeabilized with $0.3 \%$ Triton X-100 and incubated with Alexa-555 or Alexa-488 conjugate avidin. Slices were resectioned $(70-100 \mu \mathrm{m})$ and mounted on gelatin-coated slides using Mowiol mounting medium. Cells were visualized using epifluorescence microscopy (Olympus AX70) and imaged using a confocal microscope (Leica TCS SP2RS). Reconstructions were made using Neurolucida (MicroBrightField).

Statistics. We used the nonparametric two-tailed Mann-Whitney $U$ test for two-sample tests. Comparisons against a value of 1 (for normalized data) were performed with a Student's $t$ test. A one-way ANOVA was used for multiple comparisons, and a Tukey test was used for post hoc analysis. Quantifications are reported as mean \pm SEM.

\section{Results}

We focused our experiments primarily in area CA1 of neonatal mice (p5-p7), where GABAergic interneurons provide the majority of recurrent excitation (Knowles and Schwartzkroin, 1981; Deuchars and Thomson, 1996; Garaschuk et al., 1998) (and see below), when spontaneous GDPs peak in frequency (Ben-Ari, 2001; Crépel et al., 2007). GDPs were monitored using whole-cell recordings in voltage-clamp mode throughout; thus, they are observed as large inward currents in all figures.

\section{Interneurons can be optogenetically inhibited to investigate their role in GDP generation throughout the hippocampus} We observed GDPs occurring contemporaneously throughout the hippocampus: between interneurons in CA3 and CA1 (Fig. $1 A$; see Fig. $8 A$ ), between interneurons and PCs within the same region (Figs. 2, 3), and between interneurons and PCs in separate regions, as previously reported (Khazipov et al., 1997; Menendez de la Prida et al., 1998; Cattani et al., 2007). Thus, GDPs generally engage the entire hippocampal network, and data recorded from interneurons and PCs were pooled when quantifying local network activity. GDPs occurred with the same frequency in both CA 3 and CA $1(0.11 \pm 0.01 \mathrm{~Hz}$ and $0.11 \pm 0.02 \mathrm{~Hz}$, respectively, $p=0.5 ; n=14$ slices with simultaneous recordings in both regions), and in only a minority of slices (4 of 24) were they observed only in CA3. CA3 and the hilus of the dentate gyrus have been proposed to act as pacemakers for GDP initiation (Strata et al., 1997; Sipilä et al., 2005); however, we often observed GDPs in CA1 that preceded those recorded in CA3 (Fig. 1A, bottom). Thus, we quantified the occurrence and timing of GDPs recorded simultaneously in both regions $(n=14$ slices) (Fig. $1 B)$. We considered GDPs in CA3 and CA1 that occurred within $500 \mathrm{~ms}$ of each other to be synchronous events and quantified their timing difference; otherwise, the GDPs were considered to be events independent to their region. The total number of GDPs was similar between CA3 and CA1 (149 vs 150, in 14 slices); however, $23 \%$ ( 35 of 149 ) were recorded only in CA3 and 24\% (36 of 150) were recorded only in CA1. Of the total recorded synchronously, $65 \%$ ( 74 of 112 ) were recorded first in CA3, whereas 35\% (40 of 112 ) were initiated first in CA1. The timing differential was $\sim 100$ ms regardless of the site of initiation (CA3 preceding CA1: $93 \pm$ $10 \mathrm{~ms}$ vs CA1 preceding CA3: $112 \pm 13 \mathrm{~ms} ; p=0.13)$. These data are in agreement with previous studies and support the conclusion that GDPs can be generated throughout the hippocampus and even propagate from CA1 to CA3 (Garaschuk et al., 1998; Menendez de la Prida et al., 1998; Cattani et al., 2007).

Immature GABAergic interneurons are a key component of this circuitry, as the reversal potential for $\mathrm{Cl}^{-}\left(E_{\mathrm{Cl}-}\right)$ in pyramidal neurons is depolarized from rest during the first postnatal week, rendering $\mathrm{GABA}(\mathrm{A})$-mediated currents excitatory (for review, see Ben-Ari et al., 2007). To test the relative contributions of MGE- and CGE-derived interneurons, we optogenetically inhibited them by selective expression of the light-activated protonpump Arch (Chow et al., 2010; Madisen et al., 2012). In the example in Figure $1 C$, we focused yellow-green light $(545 \pm 15$ $\mathrm{nm}$ ) on either CA1 or CA3 while recording simultaneously in both regions from MGE-derived interneurons expressing Arch. Light focused on CA1 evoked a $20 \mathrm{pA}$ outward current and concomitant $10 \mathrm{mV}$ membrane potential $\left(V_{\mathrm{m}}\right)$ hyperpolarization in CA1 with little to no effect in CA3, and vice versa. The ability to evoke Arch currents in a region-specific manner was consistent across all simultaneous recordings (Fig. $1 D$, left) $(n=12$ slices with Arch expression in MGE interneurons; CA1 Light-CA1 Re- 
A

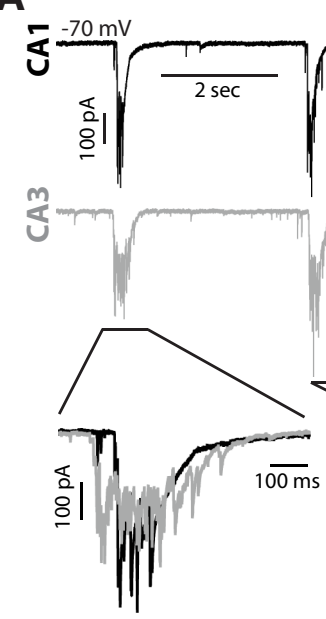

B

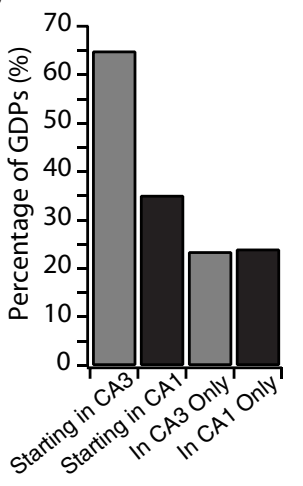

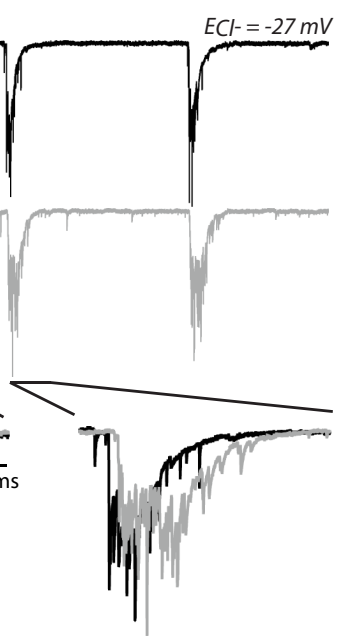

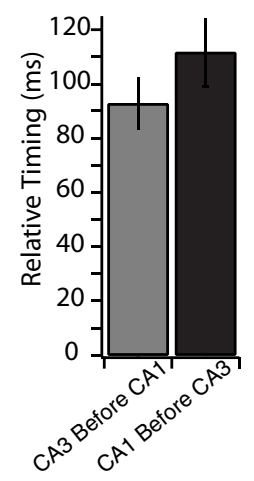

C

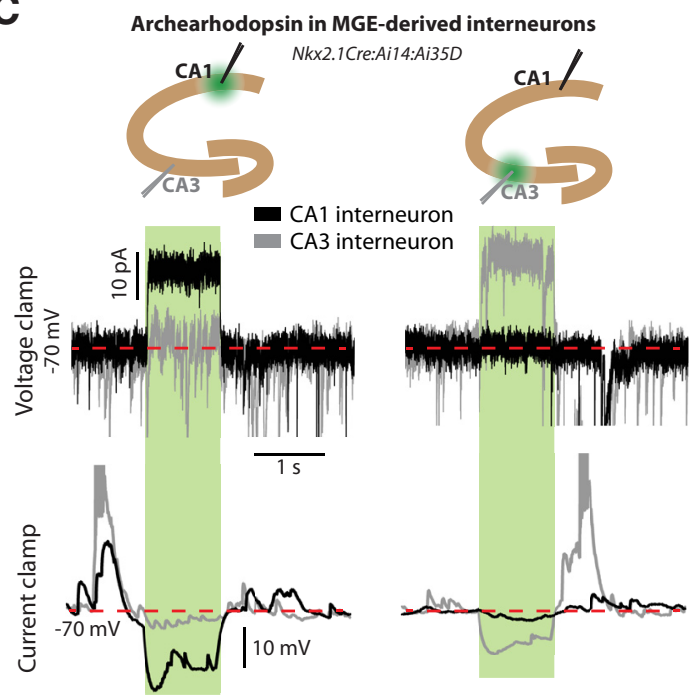

D
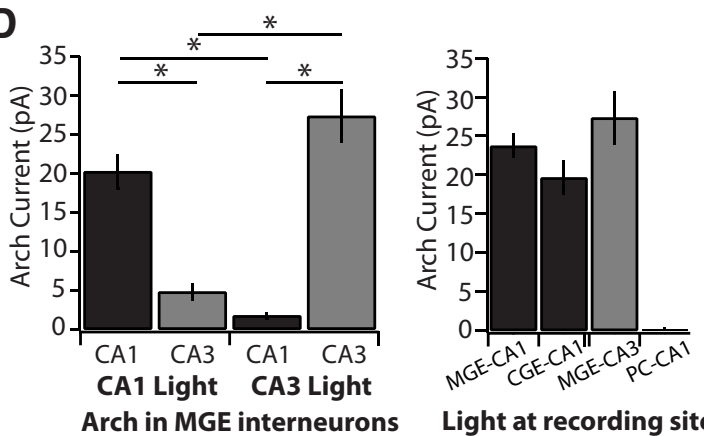

Light at recording site

$E_{i}$
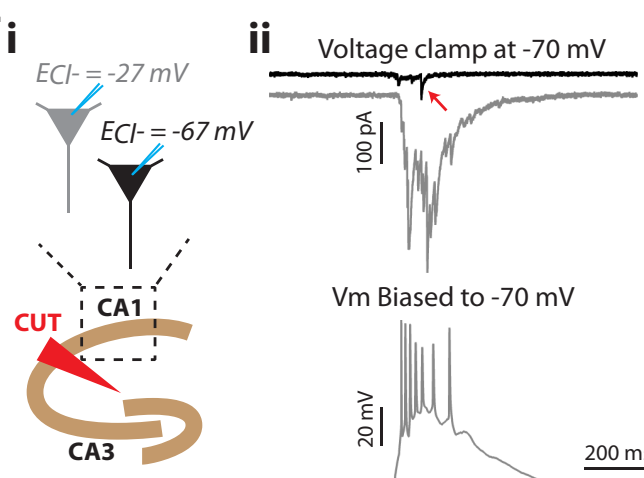

Vm Biased to $-70 \mathrm{mV}$
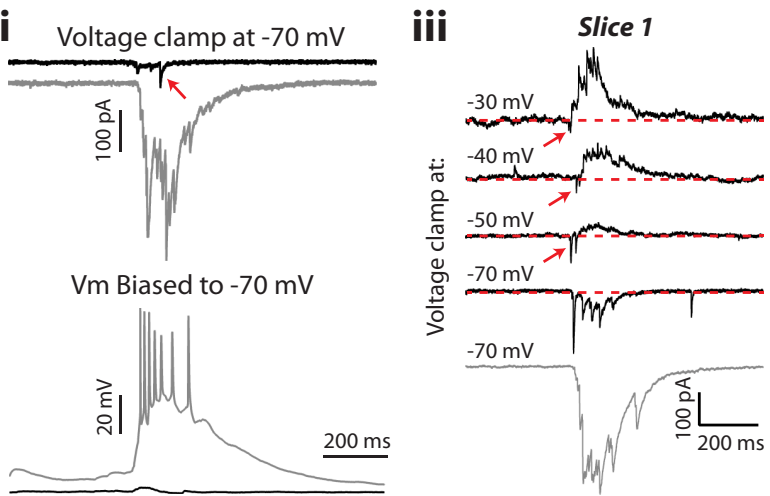

Slice 2

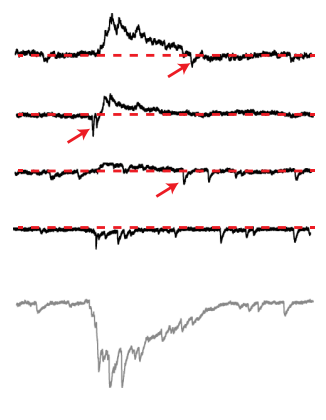

Figure 1. Characterization of GDPs and region-specific optogenetic control of interneurons with archearhodpsin. $A$, Simultaneous whole-cell voltage-clamp recordings of interneurons in CA1 (black trace) and CA3 (gray trace) at postnatal day 6 (p6). Spontaneous GDPs (observed as large inward currents) co-occurred in both regions; however, the relative timing between events was variable, with some recorded first in CA3 (expanded, left) and others in CA1 (expanded, right). Holding potential $=-70 \mathrm{mV} ; E_{\mathrm{Cl}-}=-27 \mathrm{mV}$. B, Left, Breakdown of spontaneous $\mathrm{GDPs}$ recorded simultaneously in CA3 and CA1. GDPs were considered to be independent to a region (e.g., CA3) if no corresponding GPD occurred within $500 \mathrm{~ms}$ in the other region (e.g., $\mathrm{CA} 1)(n=14$ slices; $n=$ 149 CA3 GDPs, $n=150$ CA1 GDPs). Right, When GDPs occurred synchronously in CA3 and CA1, the time difference between events was $\sim 100$ ms regardless of which was recorded first. $C$, Simultaneous whole-cell patch recordings of MGE-derived interneurons in CA1 (black trace) and CA3 (gray trace) expressing Arch at p5. Diagrams (top) represent the locations of the recordings and focus of the light (green) to activate Arch. Light stimulus in CA1 (left) induced an outward current and membrane hyperpolarization in that region, with little to no effect in CA3. Conversely, light stimulus in CA3 (right) induced an outward current and membrane hyperpolarization in that region, with little to no effect in CA1. Voltage-clamp (top traces) holding potential $=-70 \mathrm{mV}$; current-clamp recordings (bottom traces) biased to $-70 \mathrm{mV}$ with holding current. Currents and action potentials are clipped to highlight Arch-mediated currents and hyperpolarization, respectively. Green bar represents light stimulus. Dashed red line indicates baseline current and voltage. $\boldsymbol{D}$, Left, Average Arch currents recorded simultaneously in CA3 and CA1 were dependent on the light stimulus location ( $n=12$ slices). ${ }^{*} p<0.001$ (Tukey post hoc test). Right, Arch currents were evoked with similar efficacy in interneurons derived from the MGE and CGE and no current was evoked in PCs ( $n=12$ slices/cells for each condition). $\boldsymbol{E}$, Chloride-mediated currents dominate GDPs in isolated CA1. Ei, Experimental configuration: CA1 and CA3 were separated by a cut; in CA1, two neighboring PCs were recorded simultaneously with $E_{\mathrm{Cl}-}=-27 \mathrm{mV}$ (gray traces) or $-67 \mathrm{mV}$ (black traces) using two different intracellular solutions. Eii, $\mathrm{PCs}$ were voltage-clamped at $-70 \mathrm{mV}$. Only small transient inward currents (red arrow) and depolarization are observed during GDPs when cells are held near $E_{\mathrm{Cl}-}$. Black traces, $E_{\mathrm{Cl}-}=-67 \mathrm{mV}$. Gray traces, $E_{\mathrm{Cl}-}=-27 \mathrm{mV}$. Eiii, When voltage-clamped between $E_{\mathrm{Cl}-}$ and $E_{\text {glutamate }}$ (holding potentials: $-70,-50,-40$, and $-30 \mathrm{mV}$; black traces), outward GABAergic chloride currents dominate, but small inward glutamatergic currents are still observed (red arrows). In Slice 1 (left), inward currents are observed at GDP onset; however, this phenomenon was not observed consistently, as shown in Slice 2 (right). Black traces, $E_{\mathrm{Cl}-}=-67 \mathrm{mV}$. Gray traces, $E_{\mathrm{Cl}-}=-27 \mathrm{mV}$. 


\section{Archearhodopsin in MGE-derived interneurons}

A

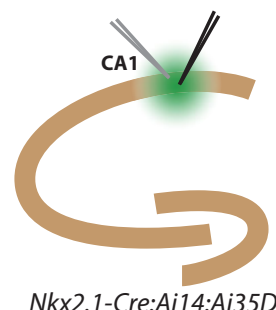

Interneuron Pyramidal cell
B

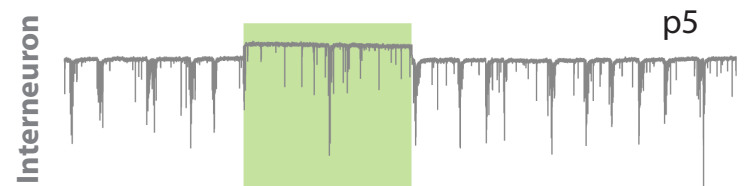

5
C

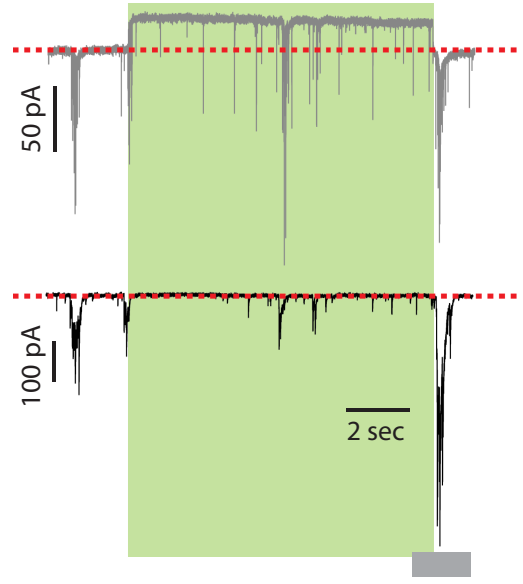

D

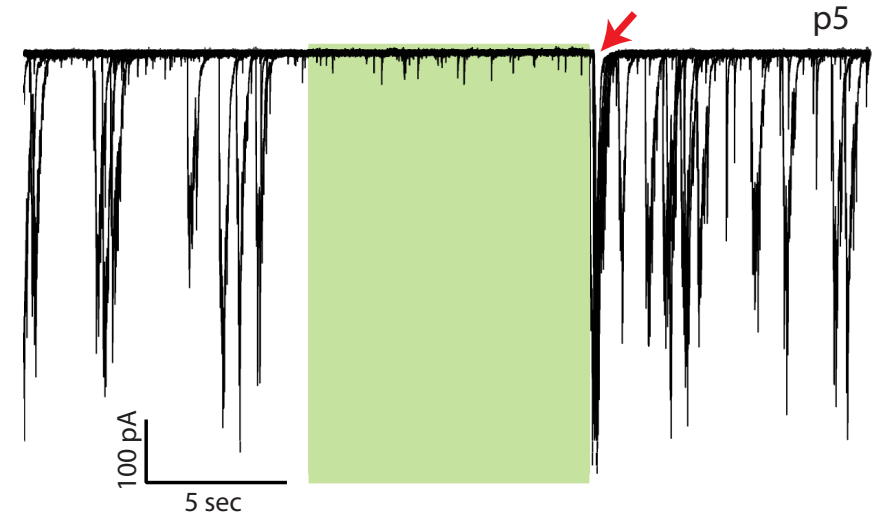

E

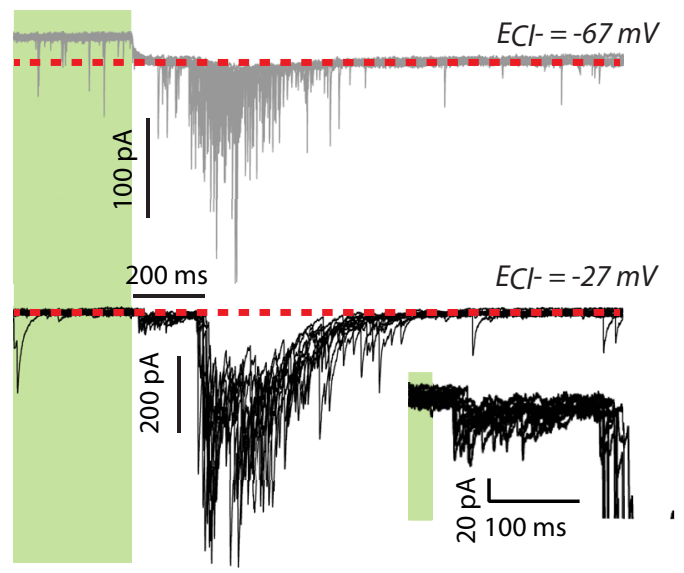

$\mathbf{F}$

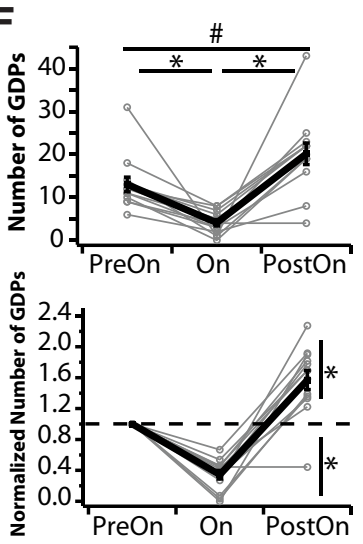

Post-rebound GDP

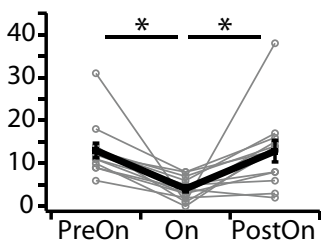

2.4

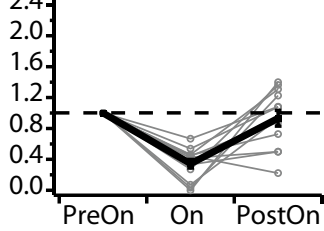

G
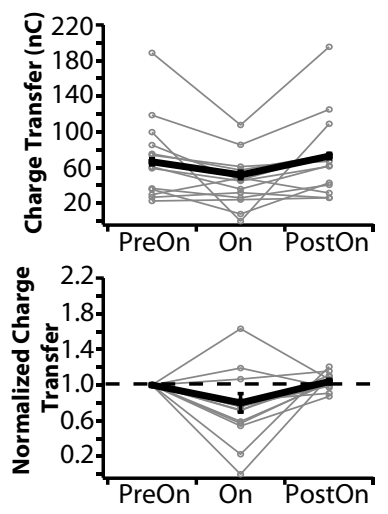
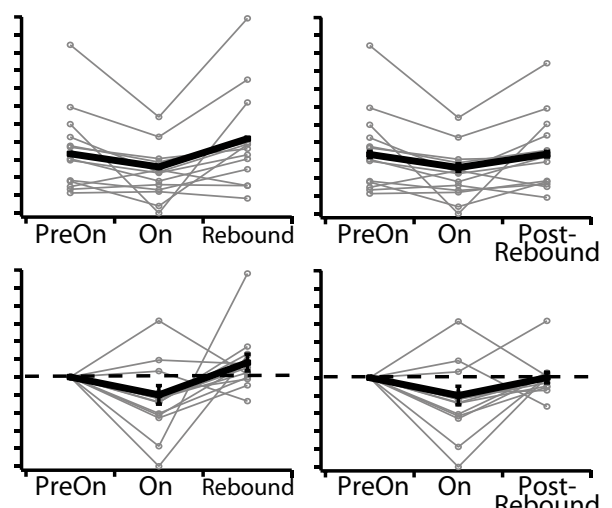

Figure 2. Arch-mediated inhibition of MGE-derived interneurons greatly suppresses spontaneous GDPs and generates rebound GDPs in CA1. A, Recording configuration with focus of yellowgreen light stimulus in CA1 to inhibit MGE-derived interneurons. B, Example of simultaneous recordings in an MGE-derived interneuron (gray) and a neighboring pyramidal cell (PC) (black) with a 10 s light stimulus (green). Activation of the Arch-current greatly reduced the frequency of spontaneous GDPs in both cells, which returned once the light was turned off. Gray bar represents region expanded in C. C, A noninactivating outward current is induced for the duration of the light stimulus ( $10 \mathrm{~s}$, green) in an Arch-expressing MGE-derived interneuron but not a neighboring PC. Dashed red line indicates baseline current. Gray bar represents region expanded in $\boldsymbol{E}$. $\boldsymbol{D}$, Second example slice demonstrating the effect Arch stimulation over multiple overlaid trials $(n=8)$ in a PC. Note triggered rebound GDPs immediately after the end of the light stimulus (red arrow). $E$, Turning off the light stimulus (green) reliably triggered a rebound GDP within $\sim 200 \mathrm{~ms}$. In this example, a barrage of PSCs was observed in the PC immediately after the end of the light stimulus and preceding the rebound GDPs (inset). Currents recorded in the interneuron (gray) are glutamatergic only $\left(E_{\mathrm{Cl}-}=-67 \mathrm{mV}\right)$, whereas those in the $\mathrm{PC}$ (black) are a mix of both $\mathrm{GABA}$ - and glutamate-mediated events $\left(E_{\mathrm{Cl}-}=-27 \mathrm{mV}\right)$. Voltage-clamp holding potential $=-70 \mathrm{mV}$ for both cells. Ten overlaid trials are shown. $\boldsymbol{F}$, Total number of GDPs (top) and normalized number of GDPs (bottom) during Pre0n, 0n, and Post0n 10 s time bins ( $n=13$ slices). At right (PostRebound), the Post0n time bin is $3 \mathrm{~s}$ after the end of the light stimulus to exclude triggered rebound GDPs. Gray represents individual experiments. Black represents population average. Total number (top): ${ }^{*} p<0.01$ (Tukey post hoc test). \#p $<0.05$ (Tukey post hoc test). Normalized data (bottom): ${ }^{*} p<0.001$ (Student's $t$ test). G, Average (top) and normalized (bottom) GDP charge transfer during the time bins described in $F$ and during rebound GDPs. The light stimulus reduces GDP charge transfer during the 0 n period in some slices ( 9 of 13 ) and increases during rebounds ( 9 of 13 ) but not consistently across the population. Black represents population mean from pooled data (top). Gray represents mean charge transfer from individual experiments. 
Archearhodopsin in CGE-derived interneurons

p6

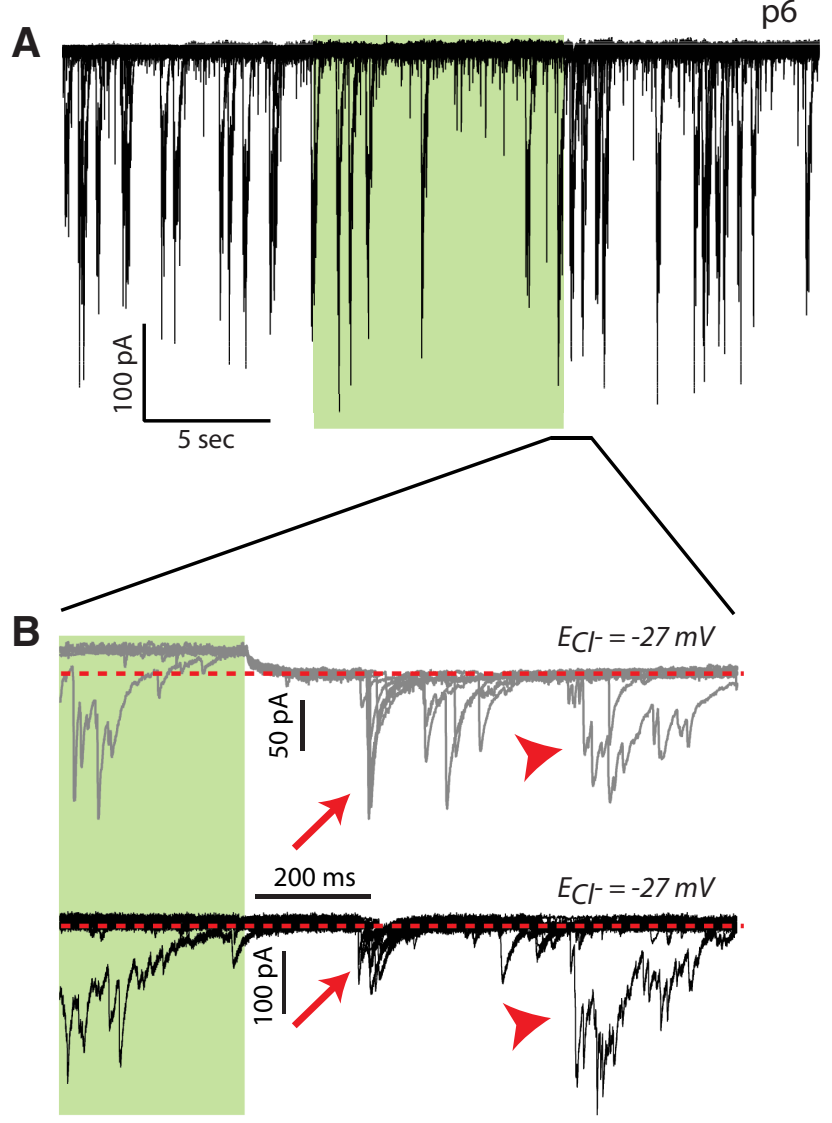

C

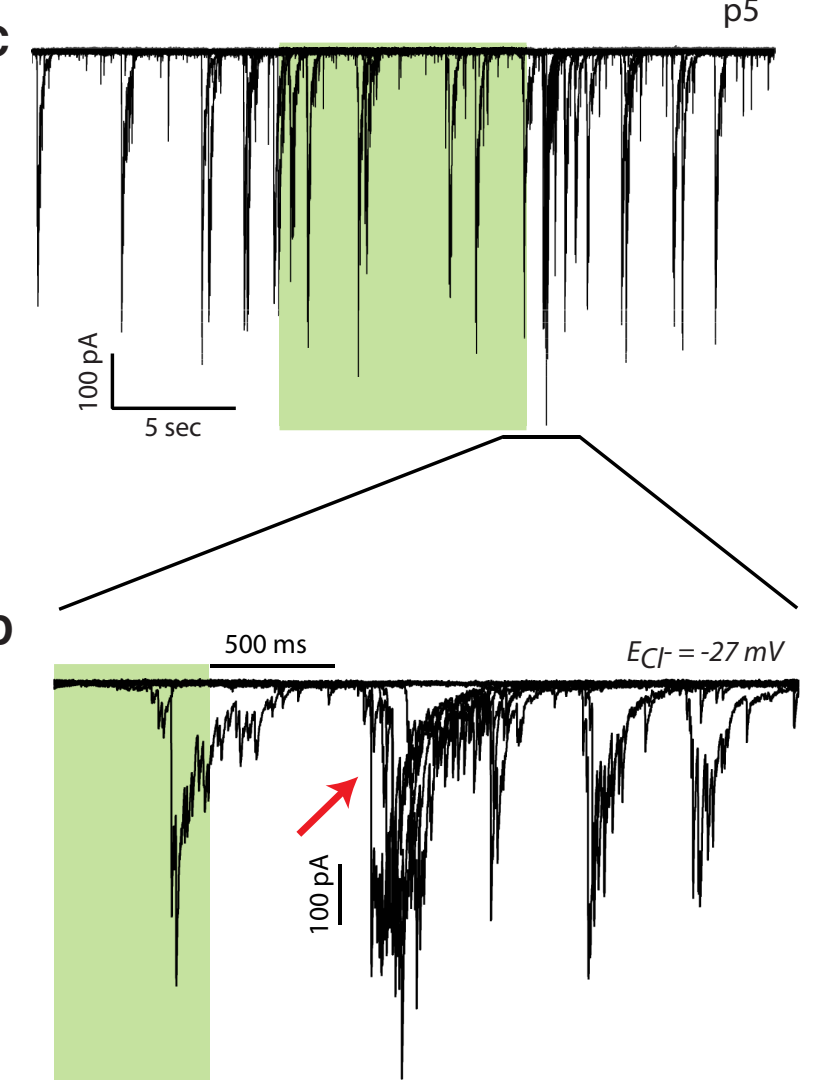

$\mathbf{E}$
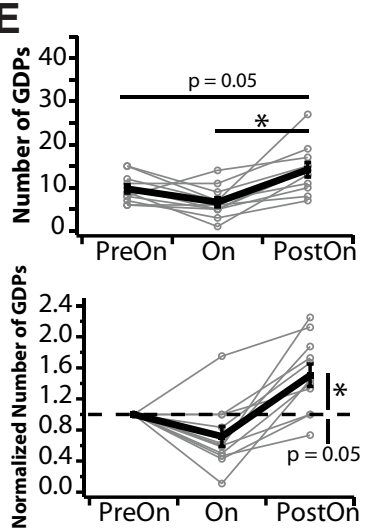
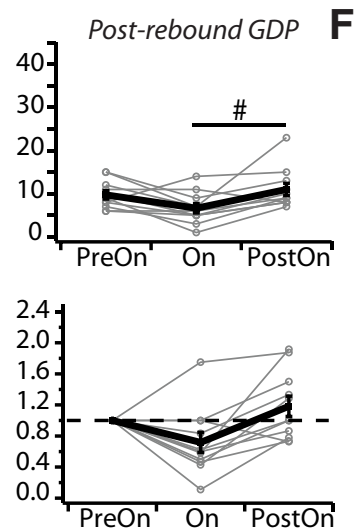

$\mathbf{F}$
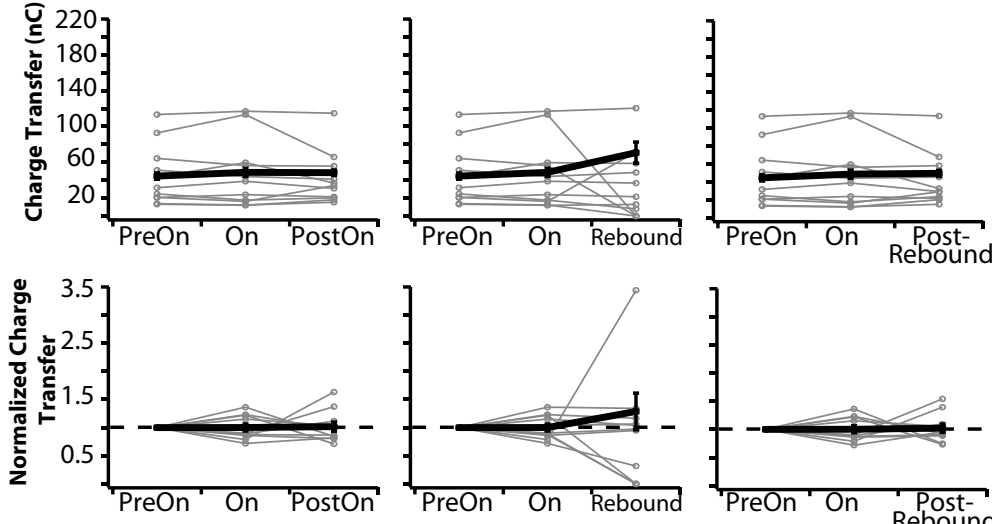

Figure 3. Arch-mediated inhibition of CGE-derived interneurons only moderately suppresses spontaneous GDPs and rarely triggers rebound GDPs in CA1. A, Example recording in a $\mathrm{PC}$ with a 10 s light stimulus (green). Activation of the Arch current did little to suppress the frequency of spontaneous GDPs. Ten overlaid trials are shown. $\boldsymbol{B}$, Expanded region from the slice in $\boldsymbol{A}$, showing both the $\mathrm{PC}$ (black) and a neighboring interneuron (gray). Turning off the light (green) does not trigger rebound GDPs when Arch is expressed in CGE-derived interneurons. Red arrows indicate that individual PSCs, but not triggered GDPs, were observed $\sim 200 \mathrm{~ms}$ after the light was turned off in both the interneuron and PC. Red arrowheads indicate a GDP that occurs $>500 \mathrm{~ms}$ after the light stimulus and is a spontaneous event. $C$, Second example recording from a PC demonstrating the modest effect of the Arch stimulus on GDP frequency (11 overlaid trials are shown). $\boldsymbol{D}$, In the majority of slices (8 of 11), turning off the light (green) induced a brief increase in network excitability after $>600 \mathrm{~ms}$. Red arrow indicates temporally correlated GDPs that occurred across multiple trials (10 overlaid trials; same experiment from C). , Total (top) and normalized (bottom) number of GDPs during the time bins described in Figure $2 F(n=11$ slices). The light stimulus caused a slight reduction in the number of GDPs, which approached significance across the population in the normalized data ( $p=0.05$, Student's t test). Total number (top): ${ }^{*} p<0.001$ (Tukey post hoctest). \#p $<0.05$ (Tukey post hoc test). Normalized data (bottom): ${ }^{*} p<0.01$ (Student's $t$ test). $\boldsymbol{F}$, Average (top) and normalized (bottom) GDP charge transfer during the time bins described in $\boldsymbol{E}$ and rebound GDPs. The charge transfer during rebound GDPs was significantly greater than during the Pre0n period in the raw data but not when normalized. No other differences were significant $(n=11$ slices).

cording: $20 \pm 2$ pA; CA1 Light-CA3 Recording: $5 \pm 1$ pA; CA3 Light-CA3 Recording: $27 \pm 3 \mathrm{pA}$; CA3 Light-CA1 Recording: $2 \pm$ $0.4 \mathrm{pA}$; one-way ANOVA: $F_{(3,44)}=2.82, p<0.001$; Tukey post hoc: CA3 Light-CA3 Recording vs CA1 Light-CA1 Recording, $p=0.06$; CA1 Light-CA3 Recording vs CA3 Light-CA1 Record- ing, $p=0.68$; all other comparisons, $p<0.001)$. Furthermore, the amplitude of the Arch current was similar regardless of interneuron embryonic lineage or the hippocampal region under focus and was absent in pyramidal cells (Fig. 1D, right) (MGECA1: $24 \pm 2$ pA; MGE-CA3: $27 \pm 2$ pA; CGE-CA1: $20 \pm 2$ pA; 
$n=12$ slices/cells for each, one-way ANOVA: $F_{(2,33)}=2.61, p=$ $0.09)$. The large $V_{\mathrm{m}}$ hyperpolarization $(11 \pm 1 \mathrm{mV} ; n=14 \mathrm{MGE}-$ derived interneurons in CA1) induced by relatively small evoked currents is due to the high Rin of immature neurons. MGEand CGE-derived interneurons had similar Rins of $310 \pm 40$ and $348 \pm 31 \mathrm{M} \Omega$, respectively $(n=19 \mathrm{MGE}, n=15 \mathrm{CGE}, p=0.38)$, with some recorded as high as $750 \mathrm{M} \Omega$. In contrast, the Rin of juvenile (p11-p21) MGE- and CGE-derived interneurons was $110 \pm 18$ and $191 \pm 26 \mathrm{M} \Omega$, respectively $(n=19 \mathrm{MGE}, n=15$ CGE, $p<0.01)$.

Thus, we were able to use Arch to effectively suppress immature interneurons in a lineage- and region-specific manner to investigate their contributions to GDP generation. In CA1, interneurons are expected to provide the primary source of local recurrent excitation (Strata et al., 1997; Garaschuk et al., 1998) due to sparse connectivity between PCs (Knowles and Schwartzkroin, 1981; Deuchars and Thomson, 1996). However, Aniksztejn et al. (2001) observed that CA1 PCs transiently make local axon collaterals during the first postnatal week that are not observed in the mature hippocampus. To test their potential contribution to GDPs, we separated CA1 from CA3 by a cut and voltage-clamped two neighboring CA1 PCs at $-70 \mathrm{mV}$ using two different internal solutions: (1) with $E_{\mathrm{Cl}-}=-67 \mathrm{mV}$ and (2) with $E_{\mathrm{Cl}-}=-27 \mathrm{mV}$ (Fig. 1Ei) (see Materials and Methods). After the cut, spontaneous GDPs were still observed in both CA1 $(n=12$ of 16 slices) and CA3 ( $n=8$ of 8 slices), in agreement with previous studies (Garaschuk et al., 1998; Menendez de la Prida et al., 1998; but see Strata et al., 1997). However, spontaneous GDP frequency was reduced in both regions relative to that observed in intact slices described above (CA1: $0.03 \pm 0.01 \mathrm{~Hz}, n=14$ cells/12 slices; CA3: $0.05 \pm 0.01 \mathrm{~Hz}, n=8$ cells/slices; one-way ANOVA: $F_{(3,46)}=8.68, p<0.001$; Tukey post hoc: CA1-Cut vs CA1-Intact, $p<0.01$; CA3-Cut vs CA3-Intact, $p<0.05$; CA1Cut vs CA3-Cut, $p=0.93)$. Importantly, in PCs recorded at a holding potential near the reversal potential for $\mathrm{GABA}(\mathrm{A})\left(E_{\mathrm{Cl}-}\right.$ set at $-67 \mathrm{mV}$ ), only sparse, small-amplitude inward currents were observed during GDPs, with little to no concomitant depolarization ( $n=13$ cells/10 slices) (Fig. 1Eii, black traces), in stark contrast to the large inward currents and depolarization observed in neighboring PCs for which $E_{\mathrm{Cl}-}$ was set at $-27 \mathrm{mV}$ (Fig. 1Eii, gray traces). Furthermore, when PCs were held at multiple voltages between the reversal potentials of glutamatergic and GABAergic conductances, outward GABAergic currents dominated the synaptic response (Fig. 1Eiii, black traces). These data demonstrate that sparse recurrent glutamatergic connections likely exist between neighboring CA1 PCs during the first postnatal week. However, GABAergic interneurons are indeed the primary source of local recurrent excitation in CA1, and we focused our investigation in this region.

\section{GDP generation is greatly reduced in CA1 when MGE-derived} interneurons are inhibited

We focused the light stimulus in CA1 and recorded simultaneously from an Arch-expressing MGE-derived interneuron and neighboring PC before, during, and after a $10 \mathrm{~s}$ light stimulus (Fig. $2 A-D$ ). In the example recording in Figure $2 B$, spontaneous GDPs occurred at a very high frequency, affording a clear example of the effect of Arch stimulation in a single trial: the light stimulus strongly suppressed ongoing GDPs in both the interneuron and PC, with spontaneous GDPs returning immediately after the light was turned off. Importantly, the Arch current was sustained throughout the $10 \mathrm{~s}$ light-on period (Fig. 2C). In a second, more typical example slice, several overlaid trials are shown, further demonstrating the strong suppression of GDPs (Fig. 2D). Interestingly, we consistently observed rebound GDPs triggered within a couple hundred milliseconds of the light being turned off (Fig. 2D, red arrow; Fig. $2 E$ is a close-up of 10 overlaid trials from cell in Fig. $2 B, C$ ). Furthermore, in the example in Figure $2 E$, barrages of PSCs can be observed in the PC immediately following the light stimulus and preceding the rebound GDPs (Fig. 2E, inset). Rebound GDPs are likely due to activation of $I_{\mathrm{h}}$ during Arch-mediated hyperpolarization, resulting in synchronous depolarization and spiking among a population of MGE-derived interneurons when they are released from inhibition (Strata et al., 1997; Vasilyev and Barish, 2002). The example traces also illustrate that GDPs observed in interneurons are composed of sustained glutamatergic and GABAergic inputs; when $E_{\mathrm{Cl}-}$ was set at the holding potential, only a barrage of excitatory PSCs were observed rather than a sustained inward current (compare interneuron recording in Fig. $2 E$ with interneurons in Fig. 1A,E, PCs).

To quantify the effect of inhibiting MGE-derived interneurons in CA1, we recorded multiple trials (at least 5) of the protocol shown in Figure $2 B$ and analyzed the GDPs recorded during four $10 \mathrm{~s}$ time bins: (1) immediately preceding the light stimulus (PreOn), (2) during the light stimulus (On), (3) immediately following the light stimulus (PostOn), and (4) $3 \mathrm{~s}$ after the end of the light stimulus to exclude triggered rebound GDPs (PostOn, PostRebound GDP). We included only experiments in which the frequency of GDPs during the PreOn bin was at least $0.05 \mathrm{~Hz}$. For the population ( $n=13$ slices), a mean of $13 \pm 1.7$ GDPs was recorded during the PreOn bin, which was reduced to $4 \pm 0.7$ during the light stimulus, and then increased to $20 \pm 2.5$ during the PostOn period, including rebound GDPs (Fig. $2 F$, top left) (one-way ANOVA: $F_{(2,36)}=19.84, p<0.001$; Tukey post hoc: PreOn vs On: $p<0.01$; PostOn vs On: $p<0.001$; PreOn vs PostOn: $p<0.05)$. PostRebound, the number of GDPs went back to the control number of $13 \pm 1.7$ (Fig. $2 F$, top right; one-way ANOVA: $F_{(2,36)}=8.07, p<0.01$; Tukey post hoc: PreOn vs PostOn: $p=0.99$; PostOn vs On: $p<0.01$ ), indicating that there was no long-lasting effect of the light stimulus on network excitability. To better compare the effect of the light stimulus across experiments, we normalized the data within each experiment to the number of GDPs recorded during the PreOn bin (Fig. $2 F$, bottom). This allowed us to quantify the magnitude of the light stimulus effect independent of the specific GDP frequency observed within each slice. With the light on, the number of GDPs significantly decreased to $0.34 \pm 0.06$ relative to the PreOn period $(p<0.001)$, and then increased to $1.57 \pm 0.12$ during the PostOn period, including rebound GPDs $(p<0.001)$. PostRebound, the normalized number of GDPs was not different relative to control $(0.93 \pm 0.1 ; p=0.51)$. Thus, optogenetically inhibiting MGE-derived interneurons in CA1 significantly reduced the frequency of GDPs, which returned to control levels after a postinhibitory rebound GDP.

Finally, we analyzed the charge transfer of GDPs recorded during the four time bins and during rebound GDPs triggered within 500 $\mathrm{ms}$ of the end of the light stimulus (Fig. $2 G$ ). Among the raw data (Fig. 2G, top), the charge transfer of rebounds GDPs was significantly greater than during the On and PostOn-PostRebound time bins, and approached significance relative to PreOn (one-way ANOVA: $F_{(4,686)}=4.11, p<0.01$; Tukey post hoc: Rebound vs On: $p<0.01$; Rebound vs PostOn-PostRebound: $p<0.05$; Rebound vs PreOn: $p=0.05$; experiment in which no GDPs were recorded dur- 
ing On period was not included). When the data were normalized to PreOn (Fig. $2 G$, bottom), there was a trend toward decreased charge transfer during the On period ( 9 of 13 slices) and increased during rebounds ( 9 of 13 slices), but the population means were not significantly different from 1 . We note that in the 3 cases in which charge transfer increased during the On period, only 1-2 GDPs were recorded in total; thus, the population data are highly sensitive to outliers. Together, these data suggest that locally suppressing MGEderived interneurons may reduce charge transfer during GDPs but that other circuits (perhaps from CA3) can in some instances compensate for their absence. Furthermore, synchronously depolarizing MGE-derived interneurons (as during rebounds) may result in increased charge transfer, but only modestly.

\section{GDP generation is only moderately reduced in CA1 when CGE-derived interneurons are inhibited}

We repeated the above experiment in CA1 in mice that express Arch in CGE-derived interneurons. Inhibition of these interneurons reduced GDP frequency much less dramatically than inhibition of those derived from the MGE, as shown for two example slices in Figure $3 A, C$. Furthermore, we rarely observed rebound GDPs triggered at the offset of the light stimulus; instead, we occasionally observed barrages of individual PSCs (Fig. 3B). However, in many slices (8 of 11), GDP frequency briefly increased $\sim 600 \mathrm{~ms}$ after the end of the light stimulus (Fig. $3 D$ ). These GDPs appeared to be clustered temporally across multiple trials; however, they were not time-locked to the end of the stimulus as observed when MGE-derived interneurons were released from inhibition (compare Figs. $2 D, E, 3 D)$.

For the population of slices $(n=11)$, a mean of $10 \pm 1$ GDPs was recorded during the PreOn bin, which was reduced to $7 \pm 1.1$ during the light stimulus, and then increased to $14 \pm 1.7$ during the PostOn period, including rebound GDPs (Fig. 3E, top left). The trend toward reduced GDP frequency during the light stimulus was not strong enough to be significantly different from the PreOn bin; however, there was a significant increase during the PostOn period (one-way ANOVA: $F_{(2,32)}=3.32, p<0.01$; Tukey post hoc: PreOn vs On: $p=0.23$; PostOn vs On: $p<0.001$; PreOn vs PostOn: $p=0.05)$. PostRebound, the number of GDPs was similar to control (Fig. $3 E$, top right) (11 \pm 1.4 ; one-way ANOVA: $F_{(2,32)}=3.32, p<0.05$; Tukey post hoc: PreOn vs PostOn: $p=0.72$; PostOn vs On: $p<0.05)$. When the data were normalized within each experiment to the PreOn bin, there was a trend toward reduced GDP frequency during the light stimulus (Fig. 3E, bottom; $0.72 \pm 0.13, p=0.05$ ). However, in two experiments, there was no change in GDP frequency, whereas in another the frequency actually increased. The number of GDPs increased to $1.51 \pm 0.14$ during the PostOn period immediately following the light stimulus $(p<0.01)$, but PostRebound was not different relative to control $(1.18 \pm 0.14 ; p=0.2)$. Thus, optogenetically inhibiting CGE-derived interneurons in CA1 resulted in only moderate and inconsistent modulation of GDPs. Furthermore, turning off the light transiently increased network excitability without triggering rebound GDPs, which returned to control levels within a few seconds.

Finally, we also analyzed the effect of inhibiting CGE-derived interneurons on GDP charge transfer. In contrast to suppressing MGE-derived interneurons, there was clearly no trend in the data comparing PreOn, On, PostOn, PostOn-PostRebound, and Rebound GDPs (Fig. $3 F$ ). Although in the raw data the charge transfer of Rebound GDPs was significantly greater than during the PreOn bin (Fig. $3 F$, top) (one-way ANOVA: $F_{(4,356)}=2.58, p<$ 0.05; Tukey post hoc: Rebound vs PreOn: $p<0.05$; three experi- ments in which rebound GDPs were not observed were not included), this was not observed in the normalized data (Fig. 3F, bottom). We conclude that any contribution of CGE-derived interneurons to GDP charge transfer is modest.

\section{MGE-derived interneurons play the most prominent role in GDP generation in CA1 likely due to higher rates of synaptic connectivity with local pyramidal cells}

We directly compared the normalized GDP data between experiments in which Arch was expressed in MGE- and CGE-derived interneurons (Fig. 4A). Importantly, inhibition of MGE-derived interneurons reduced GDP frequency significantly more than the CGE-derived cohort (MGE: $34 \pm 6 \%$ of control vs CGE: $72 \pm$ $13 \%, p<0.01)$. For both groups, GDP frequency was similarly increased following cessation of the light (Fig. $4 A$, left; MGE: $157 \pm 12 \%$ vs CGE: $151 \pm 14 \%, p=0.65)$, and returned to control levels within a few seconds (Fig. 4A, right; MGE: $93 \pm$ $10 \%$ vs CGE: $118 \pm 14 \%, p=0.3)$. However, the PostOn increase in GDP frequency could be attributed to triggered rebound GDPs in MGE- but not CGE-derived interneurons (Fig. 4B). For MGEderived, the probability of observing a GDP within $500 \mathrm{~ms}$ of the end of the light stimulus was $0.89 \pm 0.06$, which was in stark contrast to $0.16 \pm 0.07$ for CGE-derived ( $p<0.01)$. Furthermore, when rebound GDPs did occur, they were after a longer latency for CGE-derived (MGE: $224 \pm 16$ vs CGE: $285 \pm 23 \mathrm{~ms}$, $p<0.01)$. Thus, while releasing GGE interneurons from inhibition occasionally triggered GDPs, the majority were recorded several hundred milliseconds after the light stimulus ended. We conclude that MGE-derived interneurons exert a much greater influence over network excitability: inhibiting them strongly suppresses GDPs, whereas their synchronous depolarization results in reliable GDP generation.

To investigate the circuit mechanisms of GDP generation in CA1, we performed dual whole-cell patch recordings to test for synaptic connections between interneurons and PCs, in both directions. We targeted fluorescently labeled MGE- or CGEderived interneurons at two different age ranges: neonate ( 55 p8) and juvenile (p11-p21). Importantly, neonatal MGE-derived interneurons had a much higher connectivity rate with neighboring PCs than CGE-derived (Fig. 4C). In neonates, we identified connections in MGE-to-PC pairs with a $20 \%$ probability ( 9 of 45 ), compared with only $4 \%$ for CGE-derived interneurons ( 4 of 102). Similarly, we identified PC-to-MGE connected pairs in $16 \%$ ( 6 of 38 ), compared with only $2 \%$ for CGE-derived ( 2 of 88 ). Furthermore, $8 \%$ of the connections between MGE-derived interneurons and PCs were reciprocal, but no such connections were found for CGE-derived. In juveniles, although PC-to-CGE pairs were also rare $(4 \%, 3$ of 72$)$, CGE-to-PCs pairs were far more common $(16 \%, 13$ of 79$)$ than in neonates. Finally, connectivity rates for juvenile MGE-to-PC pairs were higher than in neonates $(35 \%, 18$ of 51), but PC-to-MGE and reciprocal connections were comparable (PC-to-MGE: 20\%, 10 of 51; Reciprocal: $6 \%, 3$ of 51). Thus, neonatal MGE-derived interneurons form dense recurrent synaptic connections with neighboring pyramidal cells in CA1. This likely contributes to their larger role in immature network activity, in contrast to CGE-derived interneurons, which are sparsely connected to PCs.

\section{Neonatal MGE-derived interneurons commonly make perisomatic targeting synapses with high initial release probability}

To better understand the local circuits in immature CA1, we analyzed the synaptic connections among PCs and reconstructed 
A

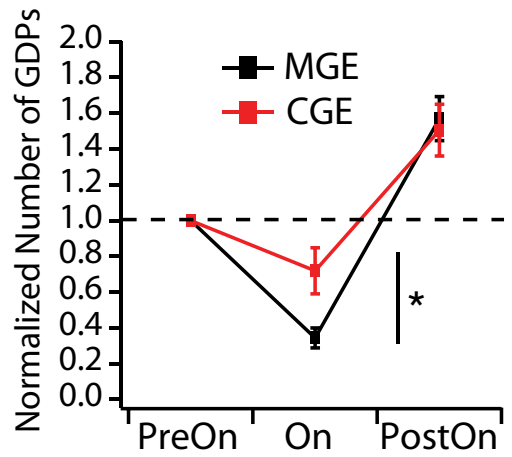

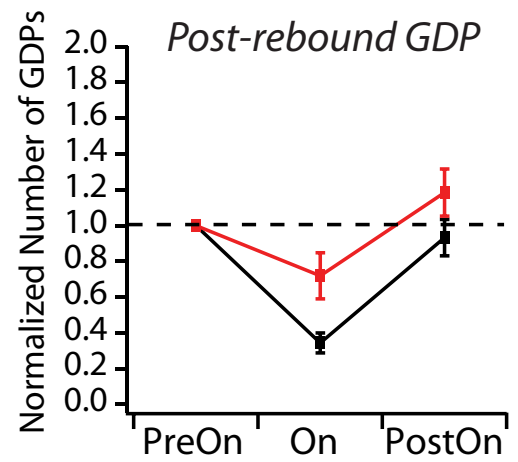

B
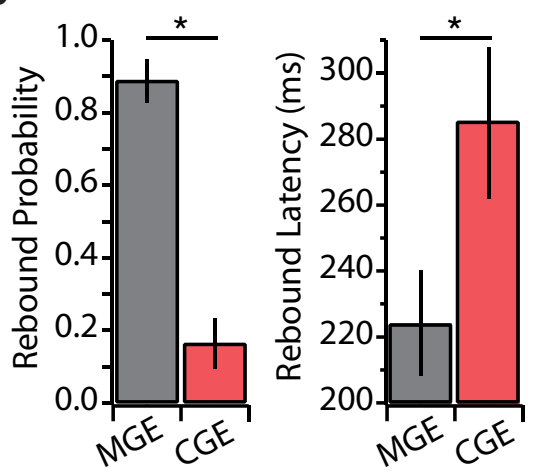

C

Connection Probabilities in CA1

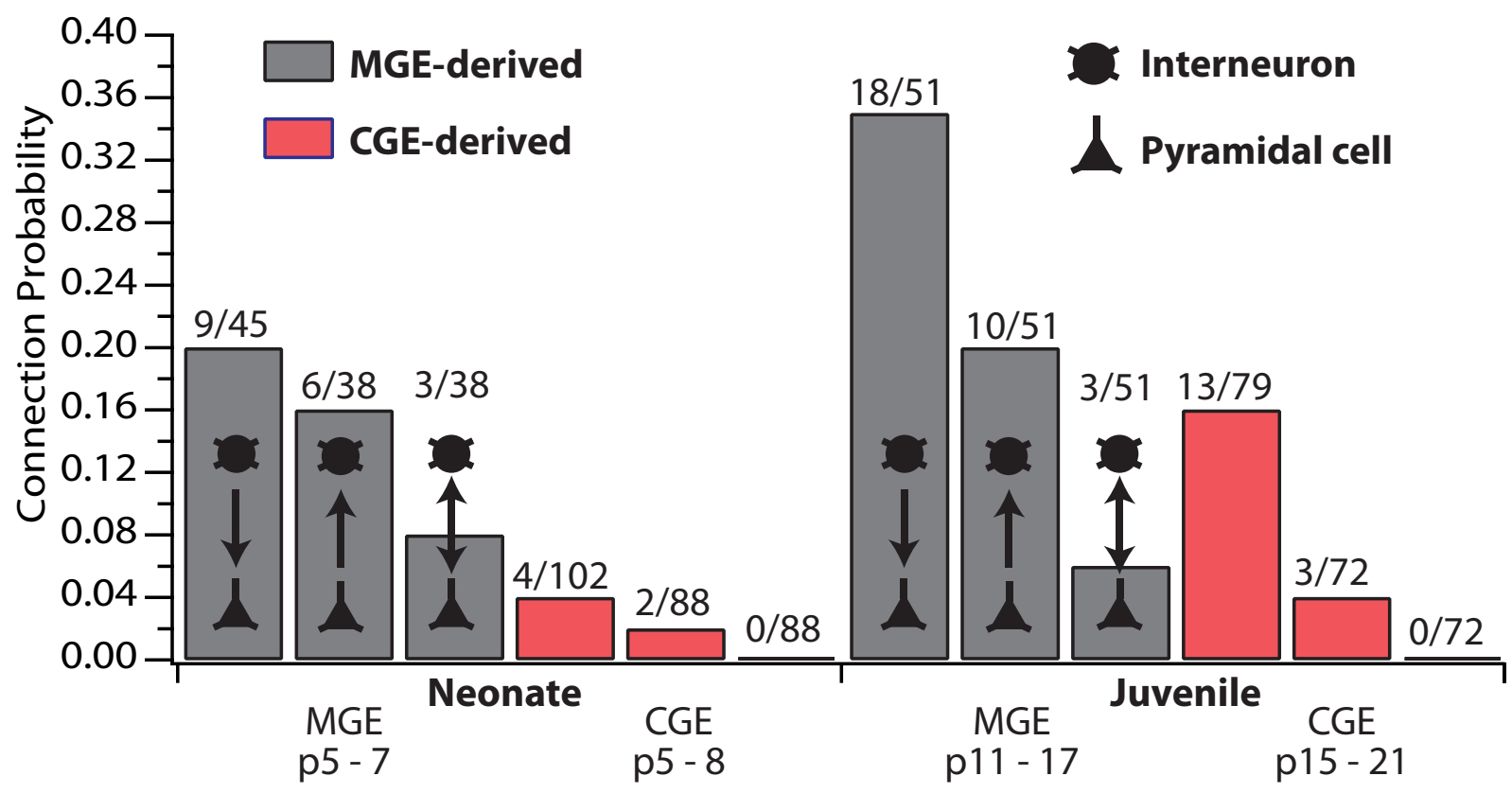

Figure 4. Inhibiting MGE-derived interneurons most strongly suppresses GDPs, likely due to their high rates of recurrent connectivity with local pyramidal cells. $A$, Comparison of the normalized number of GDPs when MGE-derived (black) or CGE-derived (red) interneurons are inhibited with Arch. GDPs were significantly more reduced when MGE-derived interneurons were inhibited. However, both exhibited a comparable increase in GDPs above baseline immediately following the light stimulus (left), which returned to control levels after $3 \mathrm{~s}$ (right, PostRebound). ${ }^{*} p<0.01$ (Mann-Whitney $U$ test). B, Left, Probability of observing a GDP within $500 \mathrm{~ms}$ of the end of the light stimulus. Right, Average latency of GDPs recorded within $500 \mathrm{~ms}$ of the end of the light stimulus. ${ }^{*} p<0.01$ (Mann-Whitney $U$ test). C, Synaptic connections were tested between interneurons and PCSin CA1 with dual whole-cell patch recordings. Shown are probabilities for finding interneuron-to-PC, $\mathrm{PC}$-to interneuron, and reciprocal connections in both neonates and juveniles. Data for CGE-derived interneurons (red) follow the same order as for MGE-derived (represented in diagrams).

interneurons. A typical example of a CA1 neonatal MGE-derived interneuron is shown in Figure $5 A$. From the Neurolucida tracing, it is clear that the axons arborized primarily within the stratum pyramidale and thus likely targeted the perisomatic region of PCs (Fig. 5A, top). Furthermore, although the membrane properties were immature, it appears likely that this cell would have developed a fast-spiking phenotype; there is a delay to spiking onset with pronounced spike after-hyperpolarization (Fig. 5A, bottom). This interneuron had reciprocal synaptic connections with a neighboring PC, which were tested with trains of presynaptic action potentials (25 at $50 \mathrm{~Hz}$ ) every $10 \mathrm{~s}$ (Fig. $5 \mathrm{~B}$, top). Postsynaptic responses were recorded in voltage clamp with a holding potential of $-70 \mathrm{mV}$; GABA(A) currents were inward due to a set $E_{\mathrm{Cl}-}$ of $0 \mathrm{mV}$ in PCs. Both the interneuron-to-PC and PC-to-interneuron synaptic connections had high probabilities of vesicle release for the first presynaptic spike (Fig. $5 B$, middle).
However, in both connections, failures were much more common during later spikes, and successful PSCs had smaller amplitudes (Fig. 5B, bottom). Despite these similarities, it is clear from the example that the EPSCs had a faster decay time constant than the IPSCs (PC-to-MGE: $1.5 \mathrm{~ms}$ vs MGE-to-PC: $7.8 \mathrm{~ms}$ ).

Among neonatal MGE-derived interneurons ( $\mathrm{p} 5-\mathrm{p} 7$ ), those classified as perisomatic targeting were common. In Figure $5 C$, additional examples are shown of reconstructed interneurons that were synaptically connected with neighboring PCs. Although two appear to be immature oriens-lacunosum moleculare (OLM) projecting (Fig. $5 \mathrm{Ci}$, far right, $\mathrm{Cii}$ ), the rest are likely to be future basket cells. Thus, we investigated the relative maturity of these perisomatic targeting MGE-to-PC connections in neonates $(n=8)$ compared with juveniles $(n=7)$. During trains of presynaptic spikes, IPSCs were depressing in both: failure rates for vesicle release increased (Fig. 5D, top), whereas quantal content decreased (Fig. 5D, bottom). 
A

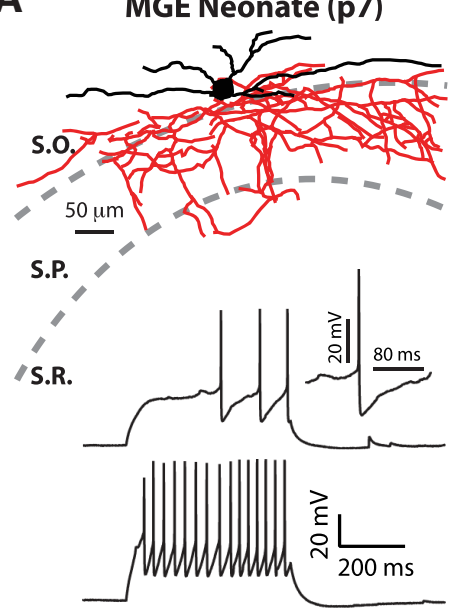

B
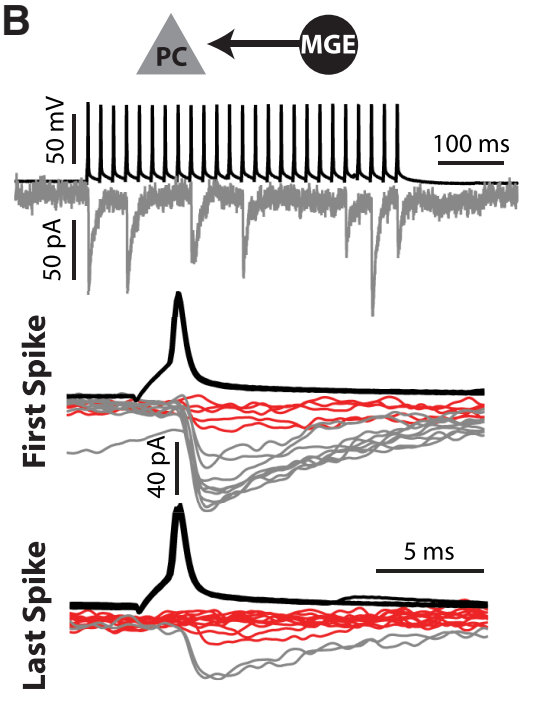

$\stackrel{P C}{\longrightarrow}$ MGE

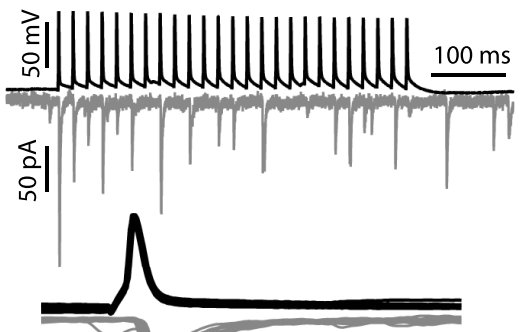

文

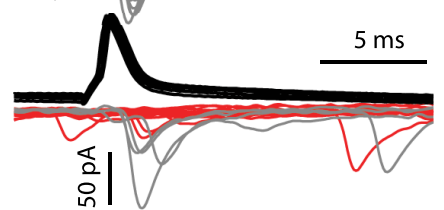

C
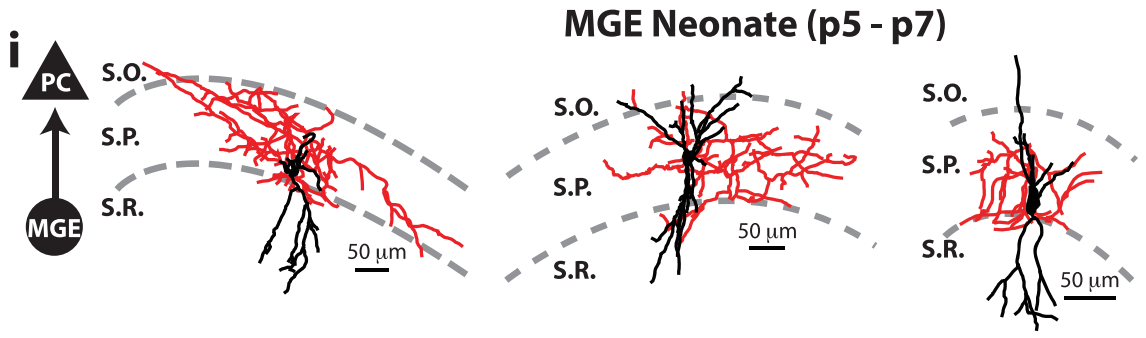

ii

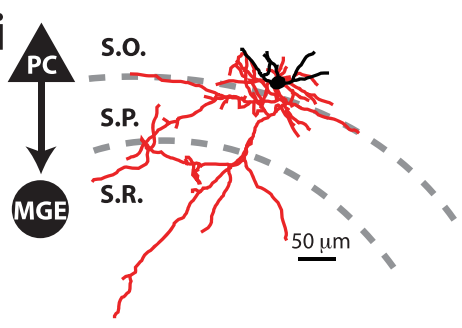

iii
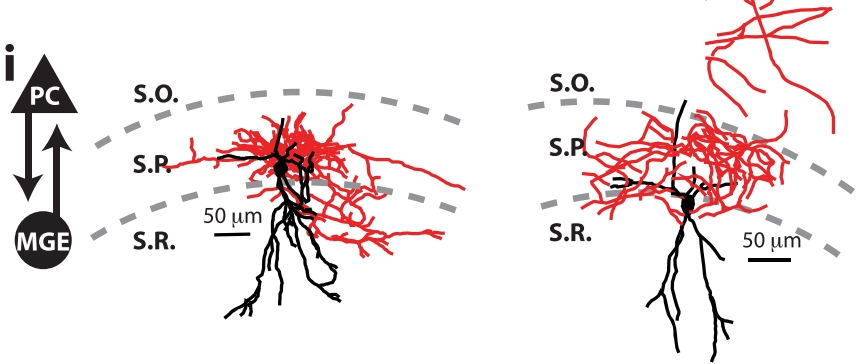

D

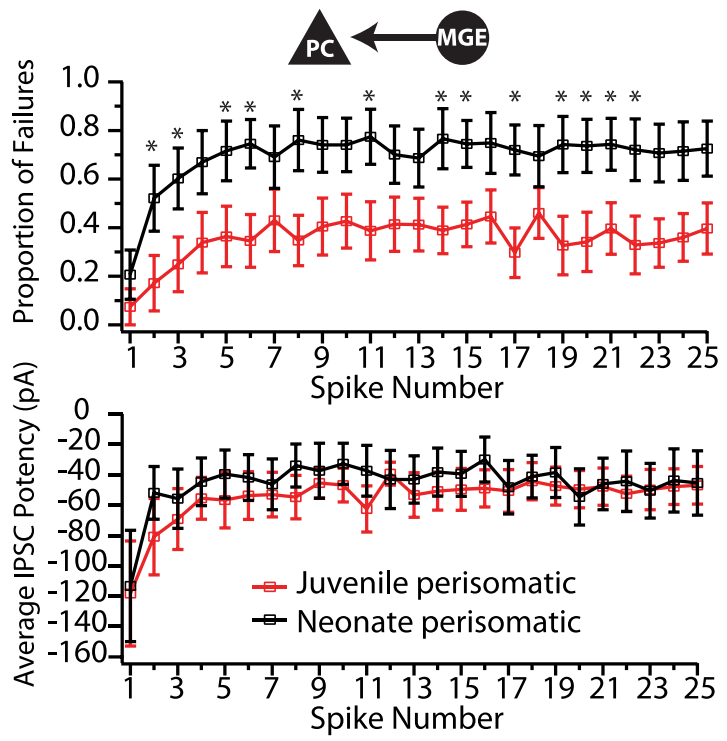

E

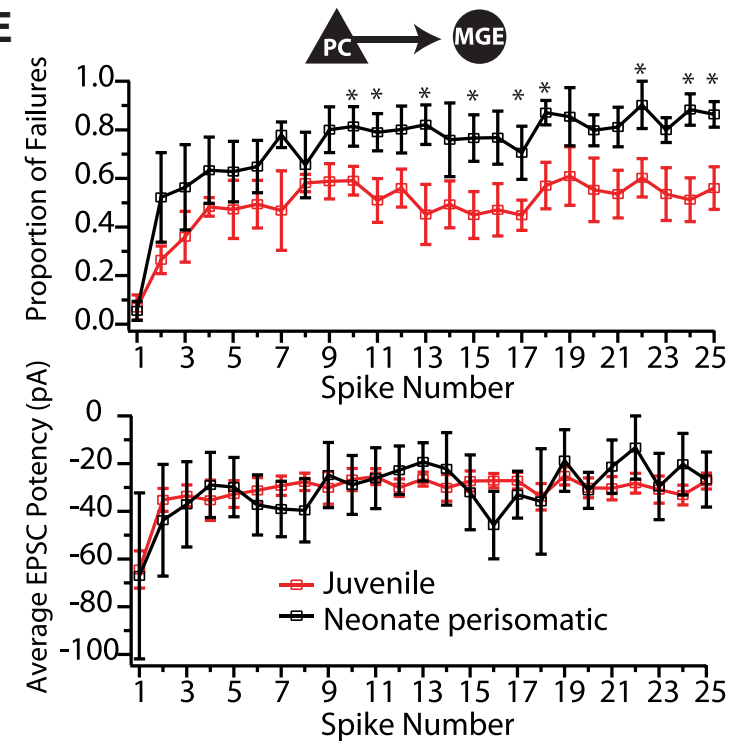

Figure 5. Neonatal MGE-derived interneurons are often perisomatic targeting, and their synaptic connections with $\mathrm{PCS}$ are mature in many respects. $\boldsymbol{A}$, Top, Neurolucida tracing of an MGE-derived interneuron at $\mathrm{p7}$. Red represents axon. Black represents soma and dendrites. The axon is largely confined to the stratum pyramidale, indicating that this cell is perisomatic targeting. S.0., Stratum oriens; S.P., stratum pyramidale; S.R., stratum radiatum. Bottom, Current pulses (160 and $240 \mathrm{pA}$ ) evoked firing responses that indicate an immature (Figure legend continues.) 
However, although release probability during the first spike was comparably high between neonates and juveniles (proportion of failures for neonate: $0.21 \pm 0.1$ vs juvenile: $0.07 \pm 0.07, p=0.5$ ), later spikes resulted in significantly more failures in neonates (Fig. $5 D$, top). In contrast, IPSC potency was comparable at both ages throughout the entire train, indicating that the total quantal content was mature by the end of the first postnatal week (Fig. 5D, bottom). Furthermore, the decay time constant of IPSCs was also mature on average in neonates (neonate MGE-to-PC: $9.3 \pm 1.4 \mathrm{~ms}$ vs juvenile MGE-to-PC: $6.9 \pm 1.0 \mathrm{~ms}, p=0.2$ ). Finally, the latency to the first IPSC was mature (neonate MGE-to-PC: $494 \pm 88 \mu$ s vs juvenile MGE-to-PC: $416 \pm 53 \mu \mathrm{s}, p=0.6$ ); however, the jitter (coefficient of variation of the latency) was greater in neonates (neonate MGE-toPC: $0.45 \pm 0.09$ vs juvenile MGE-to-PC: $0.2 \pm 0.05, p<0.05)$.

To investigate the relative maturity of $\mathrm{PC}$-to-MGE connections, we focused our analysis on neonatal perisomatic cells ( $n=4$; putative OLM cell excluded). We compared these connections with those found in juveniles that demonstrated synaptic depression (pooled: $n=3$ perisomatic targeting, $n=$ 2 dendrite targeting). These PC-to interneuron connections demonstrated similar features to those from interneuron-toPC: high initial release probability in neonates and juveniles, greater proportion of failures in neonates during later spikes, and comparable EPSC potency throughout (Fig. 5E). Furthermore, the decay time constant of the first EPSC appeared to be mature in neonates (neonate PC-to-MGE: $2.5 \pm 0.5 \mathrm{~ms}$ vs juvenile PC-to-MGE: $2.8 \pm 0.5 \mathrm{~ms}, p=0.91$ ). Finally, the latency to the first EPSC and jitter were mature (latency: neonate PC-to-MGE: $893 \pm 214 \mu$ s vs juvenile PC-to-MGE: $634 \pm$ $14 \mu \mathrm{s}, p=1$; jitter: neonate PC-to-MGE: $0.4 \pm 0.08$ vs juvenile PC-to-MGE: $0.2 \pm 0.04, p=0.09)$. In juvenile CA1, PC-to interneuron connections were common for OLM cells and demonstrated synaptic facilitation during presynaptic trains ( $n=4$ cells, data not shown), as previously reported (Ali and Thomson, 1998; Scanziani et al., 1998; Biró et al., 2005). However, such facilitation was never observed in neonates (includ-

\section{$\leftarrow$}

(Figure legend continued.) fast-spiking cell. Note delay to spike onset (top) and large afterhyperpolarization of the spike in the inset. $\boldsymbol{B}$, Synaptic connections with a neighboring $P($ made to and from the same cell shown in $\boldsymbol{A}$. Postsynaptic responses (gray) were recorded in voltage clamp with a holding potential of $-70 \mathrm{mV} ; \mathrm{GABA}(\mathrm{A})$ currents were inward due to a set $E_{\mathrm{Cl}-}$ of $0 \mathrm{mV}$ in PCs. Left, Interneuron-to-PC postsynaptic responses evoked by a train of presynaptic spikes ( 25 at $50 \mathrm{~Hz}$, top). Multiple overlaid trials are shown for the first and last spike of the train. Black traces represent presynaptic spike. Gray traces represent successful evoked vesicle release. Red traces represent release failure. The first spike evoked IPSCs with higher reliability and larger amplitudes than the last spike. Right, The PC-to-interneuron connection demonstrates similar synaptic properties, but note the faster decay time constant of the EPSC compared with IPSC at left. $\boldsymbol{C}$, Neurolucida tracings of example neonatal (p5-p7) MGE-derived interneurons found to send and receive synaptic connections with neighboring PCs in paired whole-cell recordings. Ci, Interneurons found to provide a synaptic connection to a PC. Cii, A putative OLM cell that received input from a PC. Ciii, Interneurons that were reciprocally connected with a PC. In the majority of cases, the axon targets the stratum pyramidale, indicating perisomatic connections. Black represents cell body and dendrites. Red represents axon. $\boldsymbol{D}$, Comparison of interneuron-to-PC synaptic connections between neonates $(n=8)$ and juveniles $(n=7)$ during trains of presynaptic spikes. All interneurons were classified as perisomatic targeting based on post hoc morphology. Top, Average proportion of failures as a function of spike number. Bottom, Average IPSC potency as a function of spike number. ${ }^{*} p<0.05$ (Mann-Whitney $U$ test). $\boldsymbol{E}$, Comparison of PC-to-interneuron synaptic connections between neonates $(n=4)$ and juveniles ( $n=5$ ) during trains of presynaptic spikes. All neonatal interneurons were classified as perisomatic targeting; juvenile interneurons with depressing synaptic responses were pooled from perisomatic $(n=3)$ and dendrite targeting $(n=2)$. Top, Average proportion of failures as a function of spike number. Bottom, Average EPSC potency as a function of spike number. ${ }^{*} p<0.05$ (Mann-Whitney $U$ test). ing the putative OLM cell in Fig. 5Cii); we thus excluded these connections from our analysis.

We conclude that neonatal MGE-derived interneurons are highly interconnected with neighboring PCs and commonly target the perisomatic region to provide depolarization near the spike initiation zone. Furthermore, they send and receive synaptic connections that are mature in terms of having a high initial vesicle release probability, total quantal content, latency, and PSC decay time constant. Thus, these data are consistent with our observation that interneurons play a prominent role in generating GDPs locally within CA1.

\section{Neonatal CGE-derived interneurons in CA1 exhibit asynchronous GABA release and are often dendrite targeting} As described above, connections between neonatal CGE-derived interneurons and neighboring PCs in CA1 were rare. However, when CGE-to-PC synaptic connections were found, postsynaptic responses were sustained throughout the presynaptic train and demonstrated clear asynchronous GABA release, as observed previously for many interneuron subtypes in juvenile hippocampus (Maccaferri et al., 2000; Hefft and Jonas, 2005; Daw et al., 2009). An example of a reconstructed immature cell is shown in Figure $6 \mathrm{~A}$. The axon arborized primarily in the stratum radiatum and thus targeted the apical dendrites of PCs. Action potentials from this cell evoked IPSCs in a neighboring PC that were timed locked to the first spikes but not to those that occurred later in the train (Fig. 6B, $C$ ). To quantify the degree of asynchronous vesicle release, we deconvolved the postsynaptic response with an artificial miniature IPSC (see Materials and Methods). This procedure resulted in a release rate histogram (Fig. $6 B, C$, red traces), which provides an estimate of vesicle release probability as a function of time (Diamond and Jahr, 1995; Daw et al., 2009). Overlaying histograms from multiple trials revealed that vesicle release was indeed more tightly time locked to the first spikes in the train compared with the last (Fig. $6 \mathrm{~B}, \mathrm{C}$ ). From these data, we calculated a synchronicity ratio (synchronous/asynchronous) for each spike in the train by considering the release rate during the first 5 $\mathrm{ms}$ after spike onset to be synchronous and that of the following $15 \mathrm{~ms}$ to be asynchronous (Fig. 6C). For the synaptic connection in Figure $6 B, C$, the synchronicity ratio indicated synchronous release for the first three-fourths of the presynaptic train, which then evolved into asynchronous (synchronicity ratio for first spike: 4.0 vs last spike: 0.5 ) (Fig. $6 D$ ). We performed this analysis for the three additional CGE-to-PC synaptic connections that we observed (Fig. 6E). One of these connections demonstrated similar synaptic dynamics, with initial synchronous release shifting to asynchronous (Fig. 6Ei). Another demonstrated asynchronous release throughout the entire spike train (Fig. 6Eii). Finally, the last interneuron evoked very small-amplitude IPSCs that were not amenable to generating release rate histograms but appeared qualitatively similar the cells above (Fig. 6Eiii). Thus, although rarely observed, neonatal CGE-to-PC connections generate asynchronous GABA release that outlasts the presynaptic train, demonstrating that their synaptic properties are similar to those of mature CGE-derived interneurons (Daw et al., 2009) (Fig. 7A). These synaptic properties are in stark contrast to those observed for neonatal MGE-to-PC connections described above, in which vesicle release failure was common during trains. Finally, the latency to the first IPSC and jitter were mature (latency: neonate CGE-to-PC: $1066 \pm 99 \mu$ s vs juvenile CGE-to-PC: $783 \pm 97 \mu \mathrm{s}$, $p=0.68$; jitter: neonate CGE-to-PC: $0.22 \pm 0.06$ vs juvenile CGE-to-PC: $0.19 \pm 0.02, p=0.41$ ). 


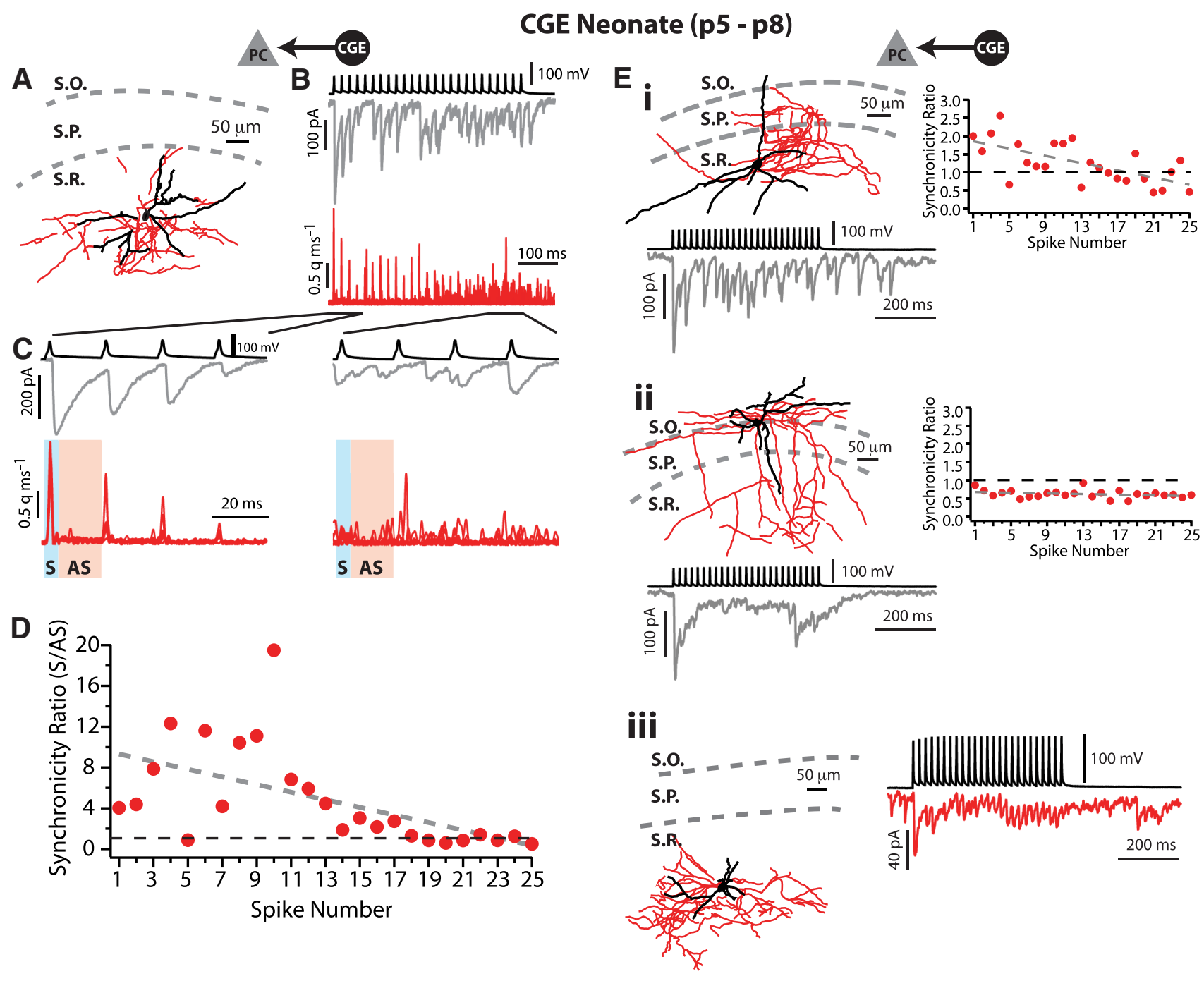

$\mathbf{F}$
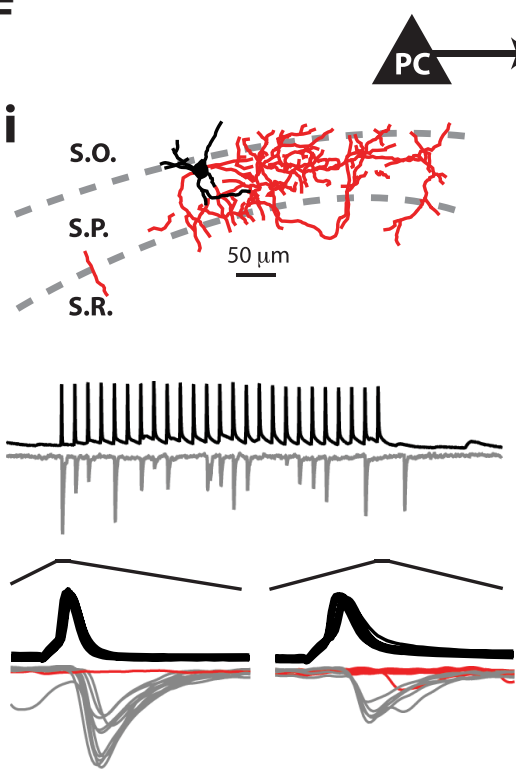

\section{CGE}

ii
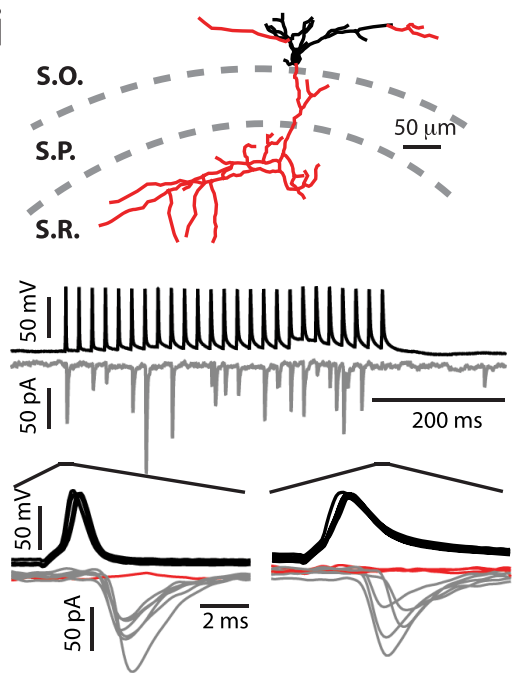

\section{G Non-connected (attempted)}

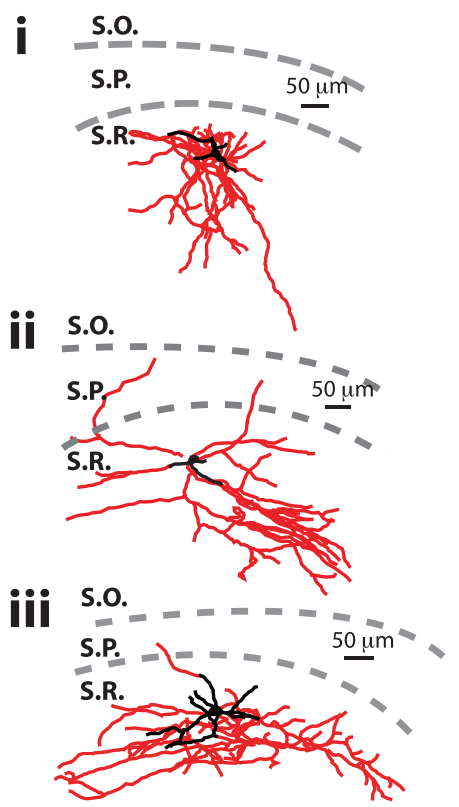

Figure 6. CGE-derived interneurons demonstrate asynchronous transmitter release and are often dendrite targeting. $\boldsymbol{A}$, Neurolucida reconstruction of a p7 CGE-derived interneuron that provided synaptic input to a neighboring PC in paired whole-cell recordings. Red represents axon. Black represents soma and dendrites. The axon is largely confined to the stratum radiatum, indicating that this cell is dendrite targeting. S.0., Stratum oriens; S.P., stratum pyramidale; S.R., stratum radiatum. $\boldsymbol{B}$, A train of presynaptic spikes (black, 25 at 50 Hz) from the cell (Figure legend continues.) 
PC-to-CGE connections were also rare in neonatal CA1. One of the two successful connections demonstrated synaptic dynamics similar to those of PC-to-MGE: the initial release probability was high, but synaptic depression occurred during a train of spikes (Fig. 6Fi). However, in the other connection, EPSC success rates and potency remained constant throughout the train (Fig. 6Fii).

We noticed that the axon of these reconstructed cells ramified primarily outside of the pyramidal cell layer; indeed, only one appears to be a future basket cell (Fig. 6Fi). Furthermore, cells for which we did not find synaptic connections were similar in their morphology and were dendrite targeting (Fig. 6G). These data are in agreement with previous findings in rat hippocampus that $\mathrm{CCK}^{+}$ interneurons, which are CGE-derived (Tricoire et al., 2011), only begin to innervate the pyramidal cell layer after the first postnatal week in CA1 (Morozov and Freund, 2003). This is in stark contrast to the neonatal MGE-derived interneurons described above, which were often perisomatic targeting (Fig. 5).

The apparent lack of perisomatic targeting CGE-derived interneurons was common only to neonates, as we regularly recorded from such cells in juvenile (p15-21) CA1 (Fig. 7A). As shown in the example, although the cell bodies of these interneurons often resided in the stratum radiatum, their axons ramified extensively in the stratum pyramidale, as observed previously (Daw et al., 2009; Tricoire et al., 2011). Furthermore, we observed that these cells were connected with high probability to neighboring PCs (juvenile perisomatic CGE-to-PC: 6 of 8, 75\%) (Fig. $7 A, B)$, similar to that observed for juvenile (p12-p17) MGEderived basket cells (perisomatic MGE-to-PC: 8 of 13, 62\%) (Fig. $7 C)$. Finally, although dendrite targeting CGE-to-PC connections were low in juveniles ( 4 of $45,9 \%$; Fig. $7 B$ ), this was still more than twice as high as observed for neonates (4 of 102, 4\%; Fig. 4C).

Thus, during the first postnatal week, perisomatic targeting CGE-derived interneurons are largely absent in CA1, appearing only later in the second postnatal week. Furthermore, synaptic

\footnotetext{
$\leftarrow$

(Figure legend continued.) shown in $\boldsymbol{A}$ evoked IPSCs (gray) in a neighboring PC (single trial shown). Red represents release rate histograms from multiple overlaid trials $(n=7)$. Note the appearance of asynchronous vesicle release at the end of the spike train. Postsynaptic responses were recorded in voltage clamp with a holding potential of $-70 \mathrm{mV}$; GABA(A) currents were inward due to a set $E_{\mathrm{Cl}-}$ of $0 \mathrm{mV}$ in $\mathrm{PC}$. Release rate histogram units represent instantaneous rate of vesicle release (quanta $\mathrm{ms}^{-1}$ ). $\boldsymbol{C}$, Expansion of the data from $\boldsymbol{B}$ for the first and last four spikes in the train. The first four spikes (left) evoke precisely time-locked IPSC s with concomitant synchronous vesicle release observable over multiple trials in the release rate histograms. In contrast, the last four spikes (right) evoke asynchronous vesicle release and IPSCs that are no longer time-locked to the spike. Blue box $(S)$ represents the $5 \mathrm{~ms}$ time region used to calculate synchronous release. Orange box (AS) represents the $15 \mathrm{~ms}$ time region used to calculate asynchronous release. $\boldsymbol{D}$, Synchronicity ratio (synchronous/asynchronous) as a function of spike number for the example synaptic connection in $\boldsymbol{B}, \boldsymbol{C}$. Calculated from the average release rate histogram ( $n=7$ trials shown in $\boldsymbol{B}, \boldsymbol{C}$ ). Dashed gray line indicates a linear fit to the data. Black dashed line at 1. $\boldsymbol{E}$, Three additional examples of neonatal CGE-to-PC synaptic connections. Neurolucida tracings represent the presynaptic interneuron (axon in red). Ei, Eii, A single trial postsynaptic IPSC (gray) is shown for clarity, but synchronicity ratios were calculated from an average of 10 release rate histograms. Dashed gray line indicates a linear fit to the data. Black dashed line at 1. Eiii, The postsynaptic response is an average of 10 IPSCs and is shown in red. $\boldsymbol{F}$, Examples of two PC-to-CGE synaptic connections. Neurolucida tracings represent the postsynaptic interneuron (axon in red). For each, a single trial of the full spike train (black) and postsynaptic response (gray) is shown at top. Expanded regions show multiple overlaid trials for the first and last spike in the train. Red traces represent failure to evoke an EPSC. $\mathbf{G}$, Examples of three reconstructed interneurons for which no synaptic connections were found with neighboring PCs (axon in red). The axon largely avoids the stratum pyramidale, similar to the example synaptically connected cells in $\boldsymbol{A}-\boldsymbol{F}$.
}

connections between neonatal CGE-derived interneurons primarily target the dendrites of neighboring PCs and are sparse. These data are consistent with our finding that inhibiting these cells only weakly suppresses GDP generation. We conclude that MGE-derived interneurons, with their early integration into the hippocampal circuitry and perisomatic innervation of PCs, are the primary drivers of recurrent excitation in developing CA1 and are likely necessary to produce GDPs in this region.

\section{MGE-derived interneurons can coordinate GDP generation and propagation between hippocampal regions}

We next asked whether MGE-derived interneurons play a comparable role in GDP generation in CA3. Furthermore, because GDPs appear capable of originating from either region (Garaschuk et al., 1998; Menendez de la Prida et al., 1998; Cattani et al., 2007) (see Fig. 1), we asked whether modulating GDPs in CA1 would affect those recorded in CA3 and vice versa. We made simultaneous recordings in CA 1 and CA3 and focused the stimulus light selectively in each region (Fig. 8A, top). As described above, Arch currents were evoked in a region-specific manner and were maintained during the entire $10 \mathrm{~s}$ stimulus (Fig. $8 \mathrm{~A}$, middle). Interestingly, we noticed that triggered rebound GDPs were consistently initiated at the site of the light stimulus and propagated to the adjacent recording site (Fig. $8 A$, bottom). Thus, GDPs triggered in CA1 can propagate to CA3.

For population analyses ( $n=13$ slices), we normalized all data within each experiment to the control condition (PreOn). Light focused in CA1 significantly reduced the number of GDPs relative to control in both regions and to a similar degree (On: CA1: $0.39 \pm 0.06, p<0.001$; CA3: $0.63 \pm 0.1, p<0.01$; CA1 vs CA3: $p=0.1$ ). Following cessation of the light, GDP frequency increased in both due to the generation of triggered rebounds (PostOn: CA1: $2.1 \pm 0.2, p<0.001$; CA3: $1.5 \pm 0.2, p<0.05$ ) (Fig. $8 B$, top left). Finally, the number of GDPs returned to control during the post-rebound period (PostOn, post-rebound: CA1: $0.95 \pm 0.1, p=0.65$; CA3: $1.03 \pm 0.1, p=0.81$ ) (Fig. $8 B$, bottom left), indicating that there was no long-lasting effect on network excitability. Thus, surprisingly, selectively inhibiting MGEderived interneurons in CA1 modulated GDPs throughout the hippocampus. The effects of focusing light in CA3, however, were more complicated. GDPs were comparably reduced in both regions (On: CA1: $0.71 \pm 0.1, p<0.05$; CA3: $0.63 \pm 0.1, p<0.05$; CA1 vs CA3: $p=0.4$ ) (Fig. $8 B$, top right); however, the reduction in CA1 was less dramatic compared with when light was focused in that region (CA1 Light-CA1 Recording: $0.39 \pm 0.06$ vs CA3 Light-CA1 Recording: $0.71 \pm 0.1, p<0.05)$. Furthermore, although GDP frequency was significantly increased in CA3 immediately following cessation of the light (PostOn: CA3: $1.79 \pm 0.2$, $p<0.01$ ), it was not in CA1 (PostOn: $1.31 \pm 0.2, p=0.08$ ). Finally, during the post-rebound period, the number of GDPs in CA3 was significantly reduced compared with control (PostOn, post-rebound: CA3: $0.72 \pm 0.1, p<0.01$ ) (Fig. $8 B$, bottom right), indicating a general dampening of network excitability immediately following the triggering of rebound GDPs.

These data suggest that GDPs recorded in CA1 are not simply a reflection of network activity originating from CA3, and that there may be considerable crosstalk between these regions. We investigated GDP propagation between CA1 and CA3 by analyzing the occurrence and timing of triggered rebound GDPs as a function of light stimulus location. Importantly, the time latency to observing rebound GDPs depended strongly on the location of the light (Fig. $8 C$, top) (one-way ANOVA: $F_{(3,375)}=109.02, p<$ 0.0001; Tukey post hoc tests for multiple comparisons). Light in 

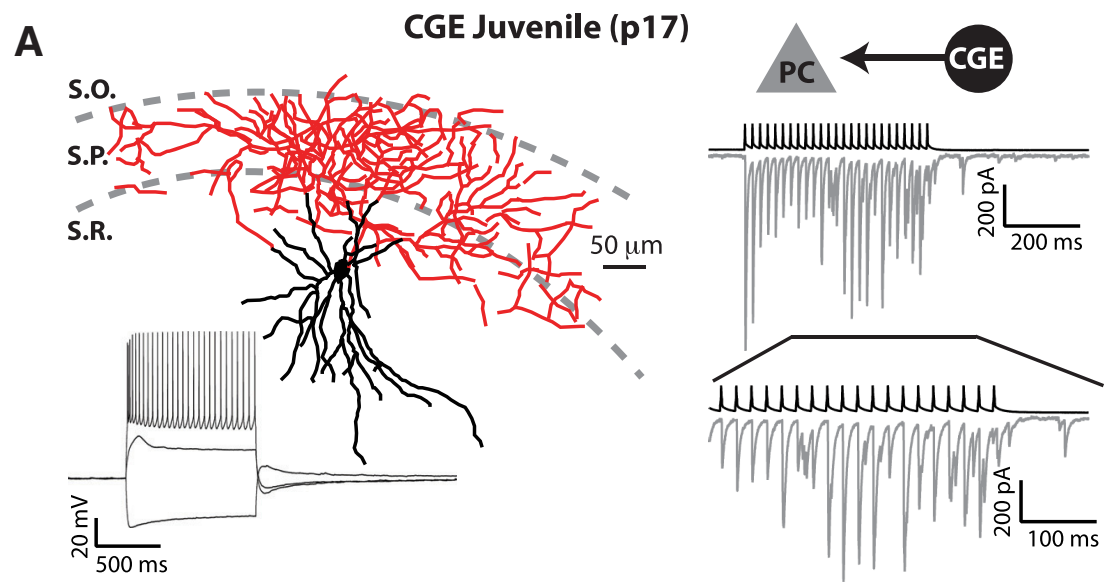

B

CGE-derived Juvenile (p15 - 21)

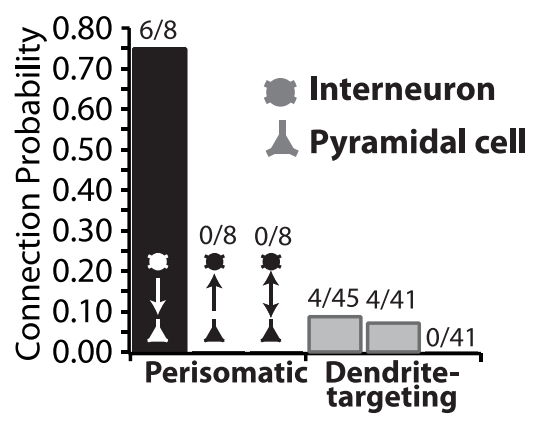

C

MGE-derived Juvenile (p12 - 17)

Figure 7. Perisomatic targeting (GE-derived interneurons are commonly found in juvenile CA1 with high rates of connectivity to neighboring PCS. A, Left, Neurolucida trace of a p17 (GE-derived basket cell (axon in red). Current pulses indicated that this cell was non-fast-spiking. S.O., Stratum oriens; S.P., stratum pyramidale; S.R., stratum radiatum. Right, Synaptic connection from the cell at left to a neighboring PC. Presynaptic spikes (black) elicited IPSCs that became asynchronous near the end of the train. Expanded region represents transition to asynchronous release. $\boldsymbol{B}$, Connection probabilities between juvenile CGE-derived interneurons and PCs in CA1. Interneurons were identified as perisomatic or dendrite targeting based on the morphology of recovered cells. Perisomatic targeting cells were common and had a high probability of CGE-to-PC connectivity. $\boldsymbol{C}$, Same as $\boldsymbol{B}$, but for juvenile MGE-derived interneurons.

CA1 triggered rebounds with significantly shorter latency in CA1 than CA3 (CA1: $241.5 \pm 6.8 \mathrm{~ms}$ vs CA3: $348.6 \pm 9.3 \mathrm{~ms} ; p<$ $0.0001)$; conversely, light in CA3 triggered rebounds with the shortest latency in CA3 (CA1: $339.1 \pm 9.8 \mathrm{~ms}$ vs CA3: $166.7 \pm 6.5$ $\mathrm{ms} ; p<0.0001)$. Interestingly, rebounds in CA3 triggered by light in CA3 occurred with a shorter latency than those triggered in CA1 by light in CA1 $(p<0.0001)$, likely reflecting differences in the underlying circuitry that generates GDPs in each region. Despite this, propagation from CA3 to CA1 and from CA1 to CA3 occurred with similar latencies ( $p=0.9$ ), perhaps due to differences in propagation velocities between them (Bolea et al., 2006). Finally, we also found that the probability of observing a rebound GDP depended on the location of the stimulus (Fig. 8C, bottom) (one-way ANOVA: $F_{(3,48)}=8.47, p<0.001$; Tukey post hoc tests for multiple comparisons). Light in CA1 triggered rebounds with a probability of $0.97 \pm 0.02$ in CA1 compared with only $0.61 \pm$ 0.1 in CA3 $(p<0.05)$; conversely, light in CA3 triggered rebounds in CA3 with a probability of $0.93 \pm 0.03$ compared with only $0.52 \pm 0.1$ in CA1 $(p<0.01)$. The probability of observing a rebound at the site of the light stimulus was similar regardless of the region under focus ( $p=0.98)$, as was the probability that it would propagate to the adjacent region $(p=0.81)$. In summary, these data suggest that MGE-derived interneurons can generate GDPs across different regions of hippocampus, and that GDPs can propagate "backwards" from CA1 to CA3. Furthermore, although there is considerable coordination of network events between CA1 and CA3, many can remain local to their region.

\section{Discussion}

Interneurons and PCs act in concert to provide mutual excitation during GDP generation (Ben-Ari et al., 1989; Bolea et al., 1999, 2007). However, interneurons are key circuit elements, as GDPs are abolished by GABA receptor antagonists, evoked by GABA agonists, share a reversal potential with GABA(A)-mediated currents, and coincide with the period during which $E_{\mathrm{Cl}-}$ is depolarizing due to low expression of the $\mathrm{K}-\mathrm{Cl}$ cotransporter $\mathrm{KCC} 2$ and high expression of the $\mathrm{Na}-\mathrm{K}-2 \mathrm{Cl}$ cotransporter 1 (Ben-Ari et al., 1989; Gaiarsa et al., 1991; Xie and Smart, 1991; Rivera et al., 1999; Yamada et al., 2004). However, no previous study has directly tested the contributions of specific interneuron subtypes to GDP generation. Here, we used optogenetics to selectively inhibit interneurons based on their embryonic lineage in a region-specific manner in the developing hippocampus in vitro. We found that neonatal MGEderived interneurons, which eventually give rise to $\mathrm{PV}^{+}$fast-spiking perisomatic targeting cells and $\mathrm{SOM}^{+}$dendrite targeting cells (Butt et al., 2005; Tricoire et al., 2011), play a prominent role in generating GDPs, particularly in CA1. These interneurons were highly interconnected with pyramidal cells during the first postnatal week, and the synapses featured many mature properties. In contrast, CGE-derived interneurons were sparsely interconnected with PCs and only moderately contributed to GDP generation.

\section{Development of interneurons and the circuitry that generates GDPs}

It has been proposed that hippocampal GDPs are generated while interneurons are primarily dendrite targeting, followed by perisomatic innervation, which coincides with the shift to inhibitory actions of GABA and the suppression of GDPs (for review, see Ben-Ari et al., 2007). In brief, early work found that GABAergic synapses are the first to form postnatally, initially between interneurons; subsequently, interneurons synapse on to PCs, but only after extension of the apical dendrite into the stratum radiatum (Tyzio et al., 1999; Hennou et al., 2002). Indeed, an investigation of $\mathrm{CCK}^{+}$interneurons, which are CGE-derived, confirmed that the axon of these cells avoids the stratum pyramidale until after the end of the first postnatal week (Morozov and Freund, 2003). These data are in complete agreement with our finding that neonatal CGE-derived interneurons are primarily dendrite targeting. However, it was suggested that these cells could be the primary contributors to GDP generation. Supporting this, cannabinoid receptor agonists, which presynaptically inhibit GABA release from $\mathrm{CCK}^{+}$interneurons, suppress GDPs 
(Bernard et al., 2005; Pelkey et al., 2015). Thus, a reasonable hypothesis is that dendrite targeting CGE-derived interneurons are the main drivers of GDPs throughout the first postnatal week. However, our data suggest that, at least in area CA1, these cells contribute to GDPs to a lesser degree than those from the MGE.

Early attempts to target immature MGE-derived basket cells for study were limited due to low PV expression in neonatal hippocampus (Nitsch et al., 1990; de Lecea et al., 1995). However, we were able to circumvent this problem by using a mouse line that expresses Crerecombinase selectively in MGE-derived cells (Xu et al., 2008). Our data unambiguously show that these interneurons strongly contribute to GDPs and make functional synaptic connections with PCs within the stratum pyramidale, at least as early as postnatal day 5 . It is notable that during neurogenesis hippocampal interneurons produced by the MGE are born before the cohort generated by the CGE (Tricoire et al., 2011). Thus, our finding that these cells appear functionally and morphologically more mature is not surprising, and it is likely that they are among the earliest cells integrated into the developing circuitry. Indeed, Allène et al. (2012) found that participation of CGEderived interneurons in GDPs correlates with their birth date; a similar temporal correlation likely exists for the earlier born MGE-derived cells. Interestingly, studies of the developing neocortex also suggest a role for MGE-derived interneurons in generating GDPs. Using paired whole-cell recordings, Pangratz-Fuehrer and Hestrin (2011) found connectivity rates between neonatal $\mathrm{PV}^{+}$basket cells and PCs in layer $5 / 6$ of visual cortex that were similar to the rates we observed in hippocampal CA1. However, these neocortical connections were observed only after postnatal day 5, which coincides temporally with the emergence of GABAmediated GDPs in deep layers of neocortex (Allène et al., 2008).

We observed the most striking suppression of GDPs during inhibition of MGEderived interneurons in CA1. In the mature hippocampus, connectivity between neighboring PCs in CA1 is extremely rare (Knowles and Schwartzkroin, 1981; Deuchars and Thomson, 1996); however, Aniksztejn et al. (2001) noted that PCs can make transient recurrent axon collaterals in CA1 at birth. Given our results in isolated CA1, and earlier work that also highlights the prominence of GABA-mediated currents during CA1 GDPs (Garaschuk et al., 1998; Cattani et al., 2007), it is likely that the contribution of glutamatergic recurrent excitation in this region is minimal. In CA1, MGE interneurons appear to be the primary source of recurrent excitation: they send and receive excitatory connections between PCs and other interneurons. (Tukey post hoc test).

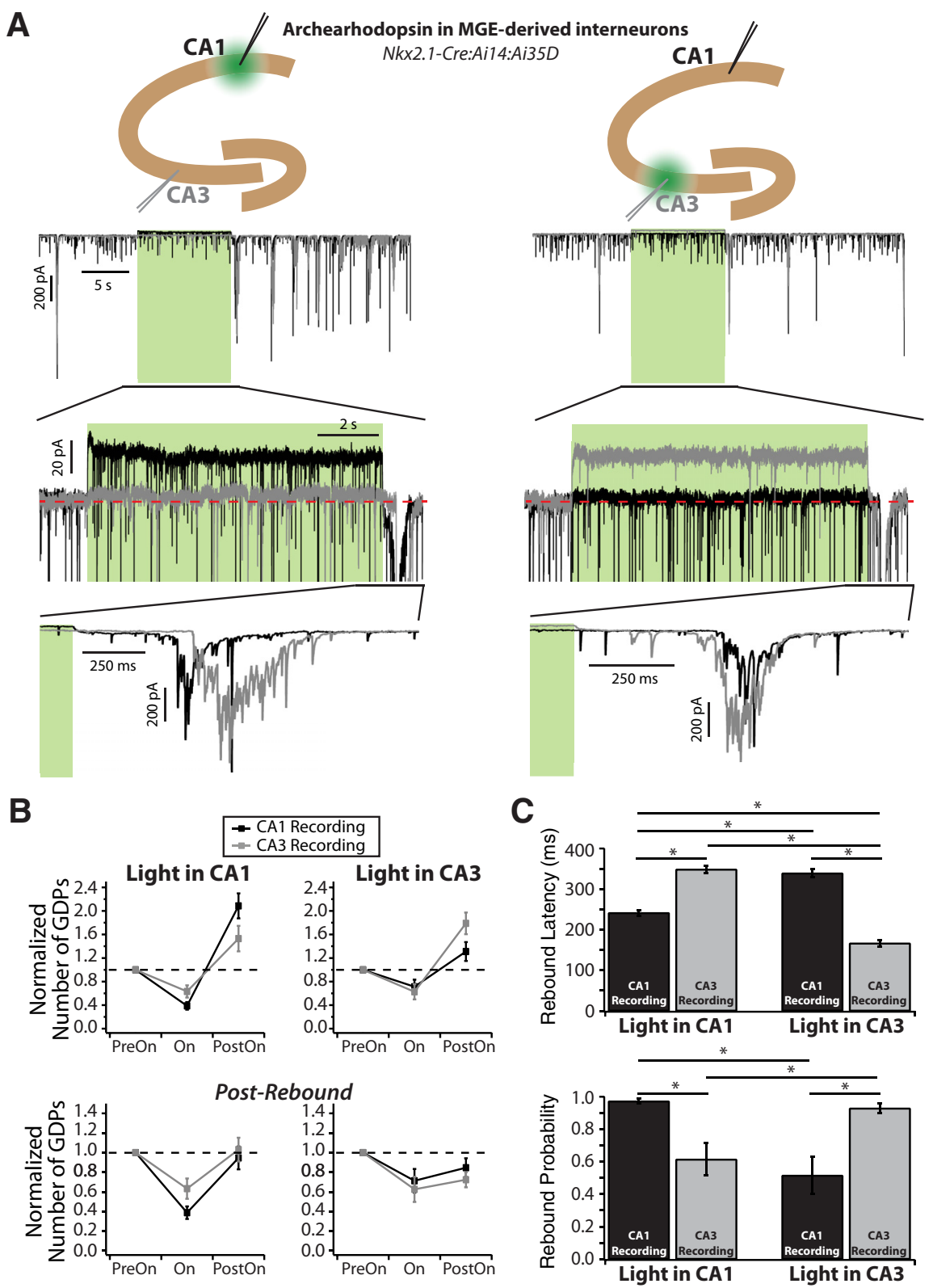

Figure 8. Inhibiting MGE-derived interneurons in CA1 modulates GDPs in CA3 and vice versa. $A$, Simultaneous recordings were made in MGE-derived interneurons in CA1 and CA3 while light was focused on either region. Top, Diagrams represent the recording configuration and locations of the light stimuli. Example recordings in CA1 and CA3 with light focused in each region. Middle, Expanded region demonstrating that Arch currents could be evoked independently in CA1 or CA3 as a function of light stimulus location. Inward currents are clipped to highlight the Arch current. Bottom, Expanded region highlighting that the relative timing of rebound GDPs in CA1 and CA3 depends on the location of the light stimulus. $B$, Normalized GDP data comparing the effect of light in CA1 versus CA3. Left column, Data collected with the light focused on CA1. Right column, Data collected with the light focused on CA3. Bottom row, The Pre0n time bin has been shifted by $3 \mathrm{~s}$ to excluded triggered rebound GDPs (PostRebound). C, Data comparing the probability of and latency to triggered GDPs in CA1 and CA3 as a function of light stimulus location. ${ }^{*} p<0.001$ nal pentraxins in MGE-derived interneurons, which results in impaired AMPA synapse formation on these cells, had no effect on GDP frequency or duration in CA3. Furthermore, GDPs persisted into the second postnatal week, suggesting that these interneurons contribute primarily to their suppression as GABA becomes inhibitory. These data seem at odds with those of the present study; however, as a constitutive knock-out, it is possible that compensatory mechanisms were activated to maintain GDP frequency. Indeed, Sipilä et al. (2009) showed that knock-out of 
the Na-K-2Cl transporter 1 (NKCC1), which maintains the neonatal depolarizing chloride gradient, also did not abolish GDPs. Amazingly, CA3 PCs developed an increase in intrinsic excitability, which facilitated GDP generation in the absence of depolarizing GABA from interneurons (Sipilä et al., 2009). An additional consideration is that, with recurrent excitation among PCs, CA3 possesses multiple mechanisms to generate GDPs. For example, connections between neonatal CA3 interneurons is shunting rather than depolarizing (Banke and McBain, 2006); thus, it is possible that reducing excitatory input onto them may paradoxically promote GDPs under some circumstances. Finally, Pelkey et al. (2015) also found that cannabinoid agonists suppressed GDPs in both wild-type and knock-out animals, complimenting previous work (Bernard et al., 2005) and implicating CCKexpressing interneurons in GDP generation. Although it is possible that CGE-derived interneurons play a greater role in CA3 than CA1, we note that cannabinoid agonists also suppress excitatory synaptic transmission from hippocampal pyramidal cells (Ohno-Shosaku et al., 2002; Kawamura et al., 2006). Thus, it is difficult to disambiguate the circuit mechanisms responsible for cannabinoid modulation of early recurrent network activity.

\section{Coordination of GDPs across the hippocampus}

We observed clear evidence that GDPs can be initiated in CA1 and propagate to CA3, and that suppression of GDPs in one region affects the frequency of events in the other. Thus, whereas GDPs may be more likely to initiate in CA3 (Menendez de la Prida et al., 1998; Sipilä et al., 2005; Bolea et al., 2006), network activity is likely coordinated across hippocampal regions, as previously proposed by Menendez de la Prida et al. (1998). Longrange projecting interneurons are a strong candidate mechanism for such coordination. Hennou et al. (2002) identified interneurons projecting from CA1 to CA3 as early as the day of birth. Furthermore, GABAergic hub cells have been described that are highly interconnected both within local circuits and across hippocampal regions, and importantly contribute to GDPs (Bonifazi et al., 2009; Picardo et al., 2011). In the present study, we also observed interneurons in CA1 that projected long distances toward CA3, including those derived from both the MGE (Fig. 5Ci, far right) and CGE (data not shown). Interestingly, interneurons that project from CA1 to CA3 are not a transient feature of neonatal circuits but are also found in the mature hippocampus (Sik et al., 1994; Craig and McBain, 2015).

In conclusion, the full set of circuit mechanisms capable of generating GDPs are complicated, potentially varied across hippocampal regions, and clearly involve the coordinated activity of pyramidal cells, MGE-derived, and CGE-derived interneurons. However, we propose that MGE-derived interneurons are particularly important for initiating recurrent network activity in the developing hippocampus: inhibiting them strongly suppressed GDPs, whereas releasing them from inhibition reliably triggered GDPs. Furthermore, many were perisomatic targeting, and are likely examples of local hubs, given their high rates of synaptic connectivity with neighboring PCs in CA1. Indeed, Bonifazi et al. (2009) described a subset of local hub cells in CA3 that were clearly baskets and capable of triggering GDPs when stimulated to fire action potentials. Although the embryonic lineage of these cells was not described, it is likely that they were MGE-derived. Recently Khalilov et al. (2015) found that, at least in CA3, GABAmediated currents are depolarizing only at the onset of GDPs, and subsequently become hyperpolarizing and shunting. It is possible that the high initial release probability of neonatal MGE-derived cells specifically supports GDP initiation, whereas long-lasting asynchronous GABA release from CGEderived interneurons contributes to GDP cessation. Future work is necessary to fully elucidate the roles of distinct interneuron subtypes; however, genetic tools are now available to parse these immature circuits.

\section{References}

Ali AB, Thomson AM (1998) Facilitating pyramid to horizontal oriensalveus interneurone inputs: dual intracellular recordings in slices of rat hippocampus. J Physiol 507:185-199. CrossRef Medline

Allène C, Cattani A, Ackman JB, Bonifazi P, Aniksztejn L, Ben-Ari Y, Cossart R (2008) Sequential generation of two distinct synapse-driven network patterns in developing neocortex. J Neurosci 28:12851-12863. CrossRef Medline

Allène C, Picardo MA, Becq H, Miyoshi G, Fishell G, Cossart R (2012) Dynamic changes in interneuron morphophysiological properties mark the maturation of hippocampal network activity. J Neurosci 32:6688-6698. CrossRef Medline

Aniksztejn L, Demarque M, Morozov Y, Ben-Ari Y, Represa A (2001) Recurrent CA1 collateral axons in developing rat hippocampus. Brain Res 913:195-200. CrossRef Medline

Banke TG, McBain CJ (2006) GABAergic input onto CA3 hippocampal interneurons remains shunting throughout development. J Neurosci 26: 11720-11725. CrossRef Medline

Ben-Ari Y (2001) Developing networks play a similar melody. Trends Neurosci 24:353-360. CrossRef Medline

Ben-Ari Y, Cherubini E, Corradetti R, Gaiarsa JL (1989) Giant synaptic potentials in immature rat CA3 hippocampal neurones. J Physiol 416: 303-325. CrossRef Medline

Ben-Ari Y, Gaiarsa JL, Tyzio R, Khazipov R (2007) GABA: a pioneer transmitter that excites immature neurons and generates primitive oscillations. Physiol Rev 87:1215-1284. CrossRef Medline

Bernard C, Milh M, Morozov YM, Ben-Ari Y, Freund TF, Gozlan H (2005) Altering cannabinoid signaling during development disrupts neuronal activity. Proc Natl Acad Sci U S A 102:9388-9393. CrossRef Medline

Biró AA, Holderith NB, Nusser Z (2005) Quantal size is independent of the release probability at hippocampal excitatory synapses. J Neurosci 25: 223-232. CrossRef Medline

Blankenship AG, Feller MB (2010) Mechanisms underlying spontaneous patterned activity in developing neural circuits. Nat Rev Neurosci 11: 18-29. CrossRef Medline

Bolea S, Avignone E, Berretta N, Sanchez-Andres JV, Cherubini E (1999) Glutamate controls the induction of GABA-mediated giant depolarizing potentials through AMPA receptors in neonatal rat hippocampal slices. J Neurophysiol 81:2095-2102. Medline

Bolea S, Sanchez-Andres JV, Huang X, Wu JY (2006) Initiation and propagation of neuronal coactivation in the developing hippocampus. J Neurophysiol 95:552-561. CrossRef Medline

Bonifazi P, Goldin M, Picardo MA, Jorquera I, Cattani A, Bianconi G, Represa A, Ben-AriY, Cossart R (2009) GABAergic hub neurons orchestrate synchrony in developing hippocampal networks. Science 326:1419-1424. CrossRef Medline

Butt SJ, Fuccillo M, Nery S, Noctor S, Kriegstein A, Corbin JG, Fishell G (2005) The temporal and spatial origins of cortical interneurons predict their physiological subtype. Neuron 48:591-604. CrossRef Medline

Cattani AA, Bonfardin VD, Represa A, Ben-Ari Y, Aniksztejn L (2007) Generation of slow network oscillations in the developing rat hippocampus after blockade of glutamate uptake. J Neurophysiol 98:2324-2336. CrossRef Medline

Chow BY, Han X, Dobry AS, Qian X, Chuong AS, Li M, Henninger MA, Belfort GM, Lin Y, Monahan PE, Boyden ES (2010) High-performance genetically targetable optical neural silencing by light-driven proton pumps. Nature 463:98-102. CrossRef Medline

Craig MT, McBain CJ (2015) Fast gamma oscillations are generated intrinsically in CA1 without the involvement of fast-spiking basket cells. J Neurosci 35:3616-3624. CrossRef Medline

Crépel V, Aronov D, Jorquera I, Represa A, Ben-Ari Y, Cossart R (2007) A parturition-associated nonsynaptic coherent activity pattern in the developing hippocampus. Neuron 54:105-120. CrossRef Medline

Daw MI, Tricoire L, Erdelyi F, Szabo G, McBain CJ (2009) Asynchronous transmitter release from cholecystokinin-containing inhibitory interneurons is widespread and target-cell independent. J Neurosci 29:1111211122. CrossRef Medline

DeFelipe J, López-Cruz PL, Benavides-Piccione R, Bielza C, Larrañaga P, 
Anderson S, Burkhalter A, Cauli B, Fairén A, Feldmeyer D, Fishell G, Fitzpatrick D, Freund TF, González-Burgos G, Hestrin S, Hill S, Hof PR, Huang J, Jones EG, Kawaguchi Y, et al. (2013) New insights into the classification and nomenclature of cortical GABAergic interneurons. Nat Rev Neurosci 14:202-216. CrossRef Medline

de Lecea L, del Río JA, Soriano E (1995) Developmental expression of parvalbumin mRNA in the cerebral cortex and hippocampus of the rat. Brain Res Mol Brain Res 32:1-13. CrossRef Medline

Deuchars J, Thomson AM (1996) CA1 pyramid-pyramid connections in rat hippocampus in vitro: dual intracellular recordings with biocytin filling. Neuroscience 74:1009-1018. CrossRef Medline

Diamond JS, Jahr CE (1995) Asynchronous release of synaptic vesicles determines the time course of the AMPA receptor-mediated EPSC. Neuron 15:1097-1107. CrossRef Medline

Gaiarsa JL, Corradetti R, Cherubini E, Ben-Ari Y (1991) Modulation of GABAmediated synaptic potentials by glutamatergic agonists in neonatal CA3 rat hippocampal neurons. Eur J Neurosci 3:301-309. CrossRef Medline

Garaschuk O, Hanse E, Konnerth A (1998) Developmental profile and synaptic origin of early network oscillations in the CA1 region of rat neonatal hippocampus. J Physiol 507:219-236. CrossRef Medline

Garaschuk O, Linn J, Eilers J, Konnerth A (2000) Large-scale oscillatory calcium waves in the immature cortex. Nat Neurosci 3:452-459. CrossRef Medline

Gonzalez-Islas C, Wenner P (2006) Spontaneous network activity in the embryonic spinal cord regulates AMPAergic and GABAergic synaptic strength. Neuron 49:563-575. CrossRef Medline

Hefft S, Jonas P (2005) Asynchronous GABA release generates long-lasting inhibition at a hippocampal interneuron-principal neuron synapse. Nat Neurosci 8:1319-1328. CrossRef Medline

Hennou S, Khalilov I, Diabira D, Ben-Ari Y, Gozlan H (2002) Early sequential formation of functional GABA(A) and glutamatergic synapses on CA1 interneurons of the rat foetal hippocampus. Eur J Neurosci 16: 197-208. CrossRef Medline

Kawamura Y, Fukaya M, Maejima T, Yoshida T, Miura E, Watanabe M, Ohno-Shosaku T, Kano M (2006) The CB1 cannabinoid receptor is the major cannabinoid receptor at excitatory presynaptic sites in the hippocampus and cerebellum. J Neurosci 26:2991-3001. CrossRef Medline

Khalilov I, Minlebaev M, Mukhtarov M, Khazipov R (2015) Dynamic changes from depolarizing to hyperpolarizing GABAergic actions during giant depolarizing potentials in the neonatal rat hippocampus. J Neurosci 35:12635-12642. CrossRef Medline

Khazipov R, Leinekugel X, Khalilov I, Gaiarsa JL, Ben-Ari Y (1997) Synchronization of GABAergic interneuronal network in CA3 subfield of neonatal rat hippocampal slices. J Physiol 498:763-772. CrossRef Medline

Klausberger T, Somogyi P (2008) Neuronal diversity and temporal dynamics: the unity of hippocampal circuit operations. Science 321:53-57. CrossRef Medline

Knowles WD, Schwartzkroin PA (1981) Local circuit synaptic interactions in hippocampal brain slices. J Neurosci 1:318-322. Medline

Li XG, Somogyi P, Ylinen A, Buzsáki G (1994) The hippocampal CA3 network: an in vivo intracellular labeling study. J Comp Neurol 339:181-208. CrossRef Medline

Maccaferri G, Roberts JD, Szucs P, Cottingham CA, Somogyi P (2000) Cell surface domain specific postsynaptic currents evoked by identified GABAergic neurones in rat hippocampus in vitro. J Physiol 524:91-116. CrossRef Medline

Madisen L, Mao T, Koch H, Zhuo JM, Berenyi A, Fujisawa S, Hsu YW, Garcia AJ 3rd, Gu X, Zanella S, Kidney J, Gu H, Mao Y, Hooks BM, Boyden ES, Buzsáki G, Ramirez JM, Jones AR, Svoboda K, Han X, et al. (2012) A toolbox of Cre-dependent optogenetic transgenic mice for light-induced activation and silencing. Nat Neurosci 15:793-802. CrossRef Medline

Meister M, Wong RO, Baylor DA, Shatz CJ (1991) Synchronous bursts of action potentials in ganglion cells of the developing mammalian retina. Science 252:939-943. CrossRef Medline

Menendez de la Prida L, Bolea S, Sanchez-Andres JV (1998) Origin of the synchronized network activity in the rabbit developing hippocampus. Eur J Neurosci 10:899-906. CrossRef Medline

Miyoshi G, Hjerling-Leffler J, Karayannis T, Sousa VH, Butt SJ, Battiste J, Johnson JE, Machold RP, Fishell G (2010) Genetic fate mapping reveals that the caudal ganglionic eminence produces a large and diverse population of superficial cortical interneurons. J Neurosci 30:1582-1594. CrossRef Medline
Morozov YM, Freund TF (2003) Postnatal development and migration of cholecystokinin-immunoreactive interneurons in rat hippocampus. Neuroscience 120:923-939. CrossRef Medline

Nitsch R, Bergmann I, Küppers K, Mueller G, Frotscher M (1990) Late appearance of parvalbumin-immunoreactivity in the development of GABAergic neurons in the rat hippocampus. Neurosci Lett 118:147-150. CrossRef Medline

Ohno-Shosaku T, Tsubokawa H, Mizushima I, Yoneda N, Zimmer A, Kano M (2002) Presynaptic cannabinoid sensitivity is a major determinant of depolarization-induced retrograde suppression at hippocampal synapses. J Neurosci 22:3864-3872. Medline

Pangratz-Fuehrer S, Hestrin S (2011) Synaptogenesis of electrical and GABAergic synapses of fast-spiking inhibitory neurons in the neocortex. J Neurosci 31:10767-10775. CrossRef Medline

Pelkey KA, Barksdale E, Craig MT, Yuan X, Sukumaran M, Vargish GA, Mitchell RM, Wyeth MS, Petralia RS, Chittajallu R, Karlsson RM, Cameron HA, Murata Y, Colonnese MT, Worley PF, McBain CJ (2015) Pentraxins coordinate excitatory synapse maturation and circuit integration of parvalbumin interneurons. Neuron 85:1257-1272. CrossRef Medline

Picardo MA, Guigue P, Bonifazi P, Batista-Brito R, Allène C, Ribas A, Fishell G, Baude A, Cossart R (2011) Pioneer GABA cells comprise a subpopulation of hub neurons in the developing hippocampus. Neuron 71: 695-709. CrossRef Medline

Rivera C, Voipio J, Payne JA, Ruusuvuori E, Lahtinen H, Lamsa K, Pirvola U, Saarma M, Kaila K (1999) The $\mathrm{K}^{+} / \mathrm{Cl}^{-}$co-transporter KCC2 renders GABA hyperpolarizing during neuronal maturation. Nature 397:251-255. CrossRef Medline

Scanziani M, Gähwiler BH, Charpak S (1998) Target cell-specific modulation of transmitter release at terminals from a single axon. Proc Natl Acad Sci U S A 95:12004-12009. CrossRef Medline

Sik A, Ylinen A, Penttonen M, Buzsáki G (1994) Inhibitory CA1-CA3-hilar region feedback in the hippocampus. Science 265:1722-1724. CrossRef Medline

Sipilä ST, Huttu K, Soltesz I, Voipio J, Kaila K (2005) Depolarizing GABA acts on intrinsically bursting pyramidal neurons to drive giant depolarizing potentials in the immature hippocampus. J Neurosci 25:5280-5289. CrossRef Medline

Sipilä ST, Huttu K, Voipio J, Kaila K (2006) Intrinsic bursting of immature CA3 pyramidal neurons and consequent giant depolarizing potentials are driven by a persistent $\mathrm{Na}^{+}$current and terminated by a slow $\mathrm{Ca}^{2+}$. activated $\mathrm{K}^{+}$current. Eur J Neurosci 23:2330-2338. CrossRef Medline

Sipilä ST, Huttu K, Yamada J, Afzalov R, Voipio J, Blaesse P, Kaila K (2009) Compensatory enhancement of intrinsic spiking upon NKCC1 disruption in neonatal hippocampus. J Neurosci 29:6982-6988. CrossRef Medline

Strata F, Atzori M, Molnar M, Ugolini G, Tempia F, Cherubini E (1997) A pacemaker current in dye-coupled hilar interneurons contributes to the generation of giant GABAergic potentials in developing hippocampus. J Neurosci 17:1435-1446. Medline

Tricoire L, Pelkey KA, Erkkila BE, Jeffries BW, Yuan X, McBain CJ (2011) A blueprint for the spatiotemporal origins of mouse hippocampal interneuron diversity. J Neurosci 31:10948-10970. CrossRef Medline

Tritsch NX, Yi E, Gale JE, Glowatzki E, Bergles DE (2007) The origin of spontaneous activity in the developing auditory system. Nature 450: 50-55. CrossRef Medline

Tyzio R, Represa A, Jorquera I, Ben-Ari Y, Gozlan H, Aniksztejn L (1999) The establishment of GABAergic and glutamatergic synapses on CA1 pyramidal neurons is sequential and correlates with the development of the apical dendrite. J Neurosci 19:10372-10382. Medline

Vasilyev DV, Barish ME (2002) Postnatal development of the hyperpolarization-activated excitatory current Ih in mouse hippocampal pyramidal neurons. J Neurosci 22:8992-9004. Medline

Wester JC, McBain CJ (2014) Behavioral state-dependent modulation of distinct interneuron subtypes and consequences for circuit function. Curr Opin Neurobiol 29:118-125. CrossRef Medline

Xie XM, Smart TG (1991) A physiological role for endogenous zinc in rat hippocampal synaptic neurotransmission. Nature 349:521-524. CrossRef Medline

Xu Q, Tam M, Anderson SA (2008) Fate mapping Nkx2.1-lineage cells in the mouse telencephalon. J Comp Neurol 506:16-29. CrossRef Medline

Yamada J, Okabe A, Toyoda H, Kilb W, Luhmann HJ, Fukuda A (2004) Cluptake promoting depolarizing GABA actions in immature rat neocortical neurones is mediated by NKCC1. J Physiol 557:829-841. CrossRef Medline 